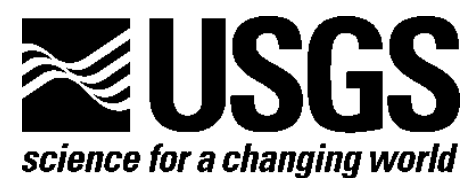

\title{
Disputes over Science and Dispute Resolution Approaches-A Survey of Bureau of Reclamation Employees
}

Open-File Report 2012-1186 


\section{U.S. Department of the Interior \\ KEN SALAZAR, Secretary}

\section{U.S. Geological Survey \\ Marcia K. McNutt, Director}

U.S. Geological Survey, Reston, Virginia: 2012

For more information on the USGS-the Federal source for science about the Earth,

its natural and living resources, natural hazards, and the environment-visit

http://www.usgs.gov or call 1-888-ASK-USGS

For an overview of USGS information products, including maps, imagery, and publications, visit $h$ ttp://www.usgs.gov/pubprod

To order this and other USGS information products, visit http://store.usgs.gov

Suggested citation:

Burkardt, Nina, and Ruell, E.W., 2012, Disputes over science and dispute resolution approachesA survey of Bureau of Reclamation employees: U.S. Geological Survey Open-File Report 2012-1186, $49 \mathrm{p}$.

Any use of trade, product, or firm names is for descriptive purposes only and does not imply endorsement by the U.S. Government.

Although this report is in the public domain, permission must be secured from the individual copyright owners to reproduce any copyrighted material contained within this report.

The findings and conclusions in this report are those of the author(s) and do not necessarily represent the views of the Bureau of Reclamation. 


\section{Contents}

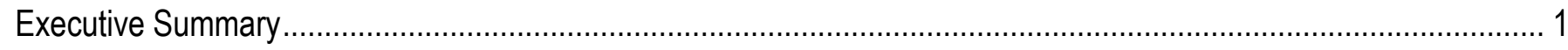

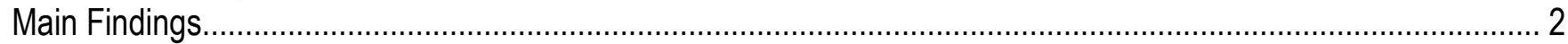

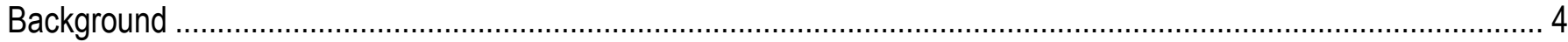

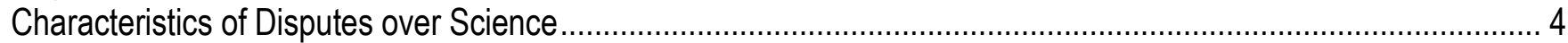

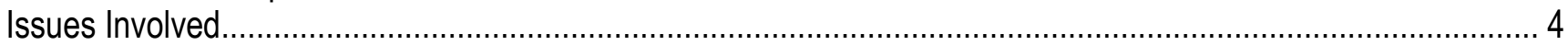

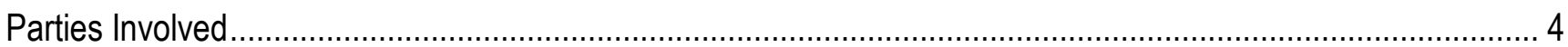

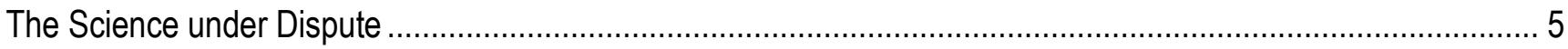

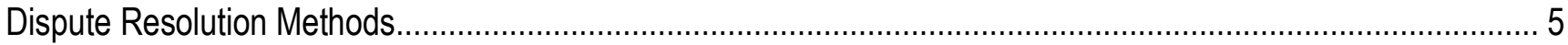

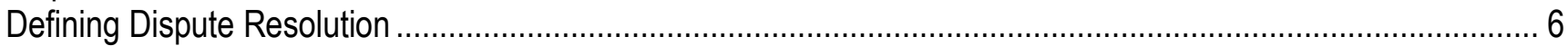

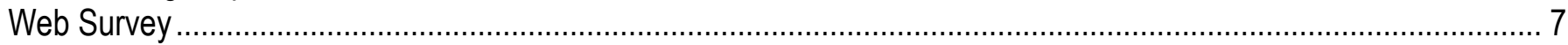

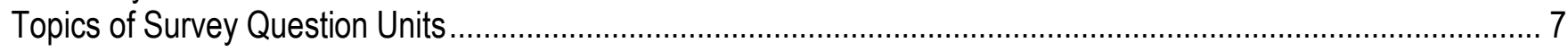

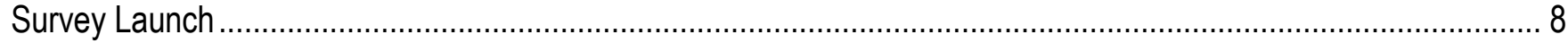

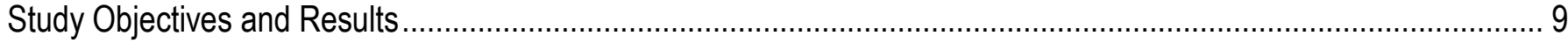

Respondents' Professional Background and Experience ............................................................................. 9

Objectives and Hypotheses ............................................................................................................

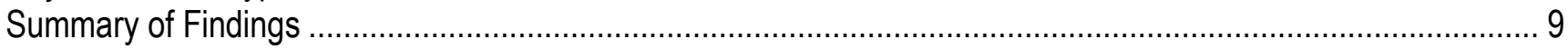

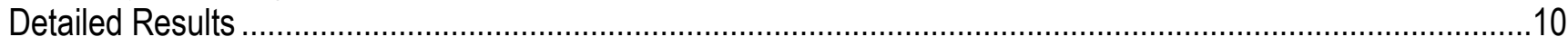

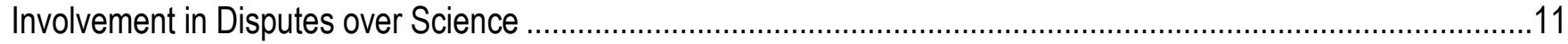

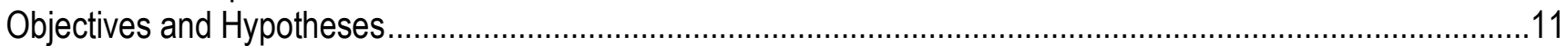

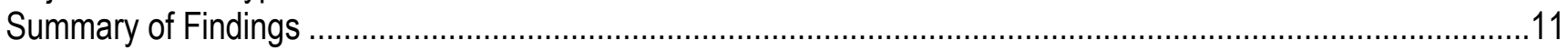

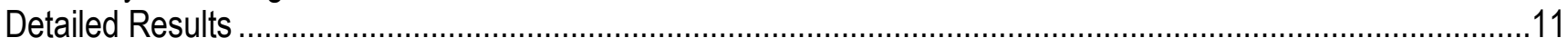

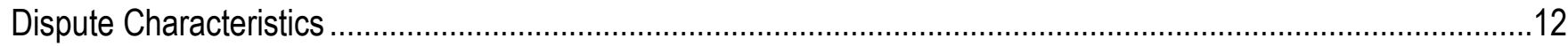

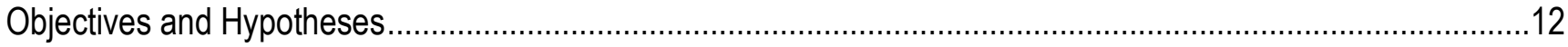

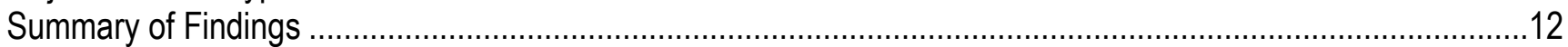

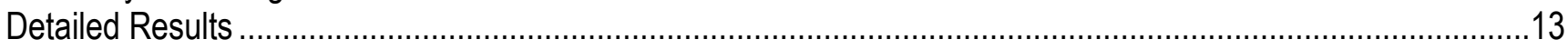

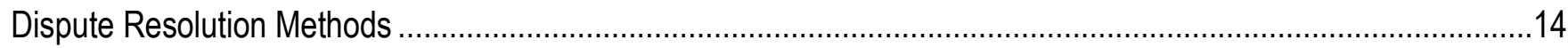

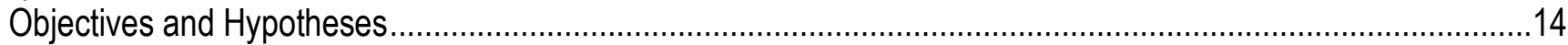

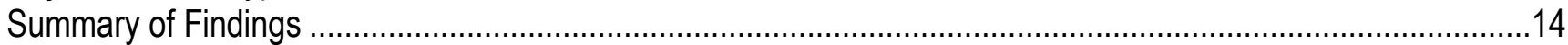

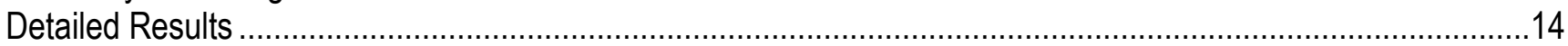

Number of Issue and Party Types Involved in Dispute Versus Method Types Used............................................15

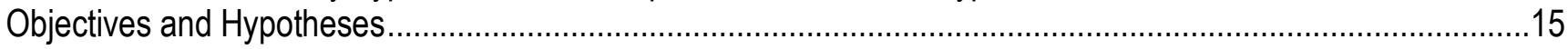

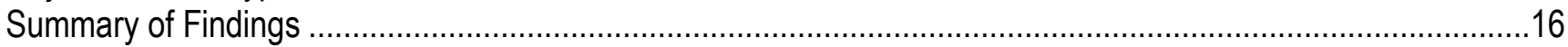

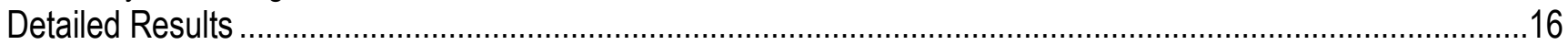

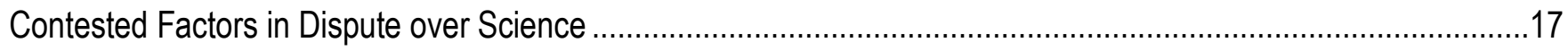

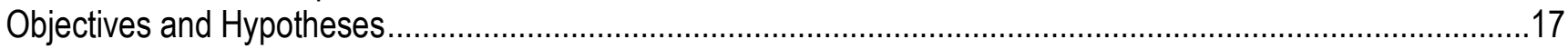

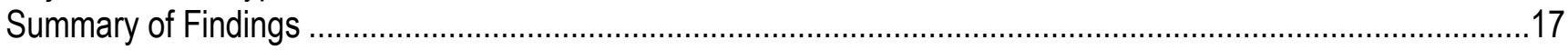

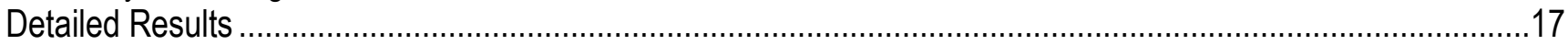

Evaluations of Performance of Dispute Resolution Method Types .................................................................17

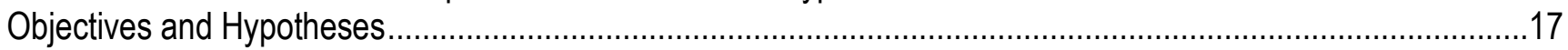

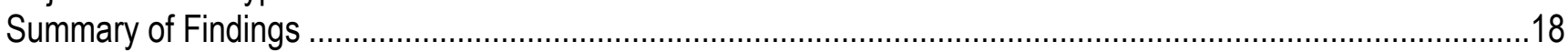

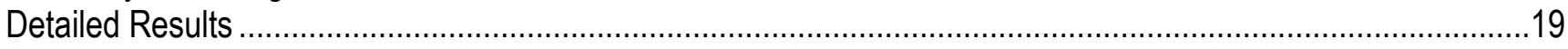

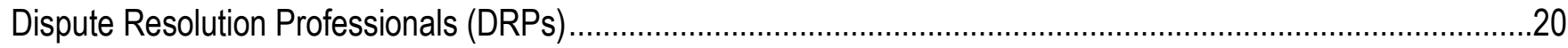

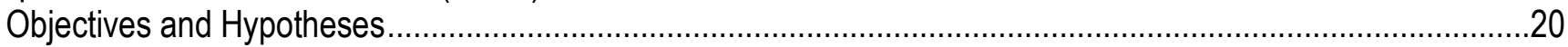

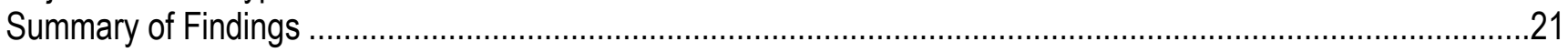

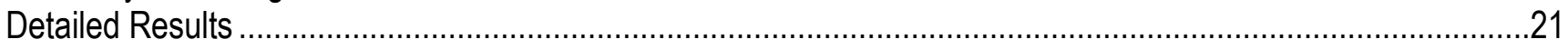

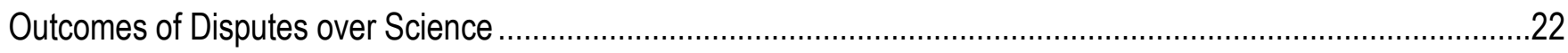




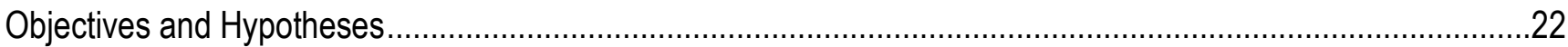

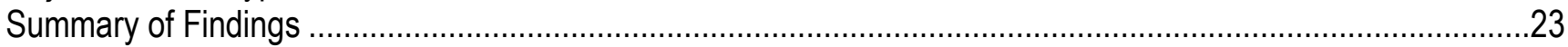

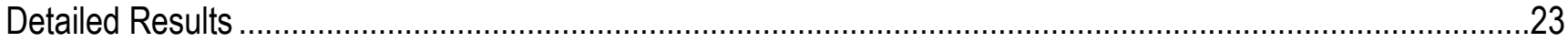

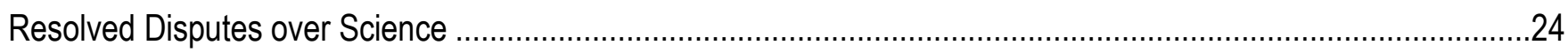

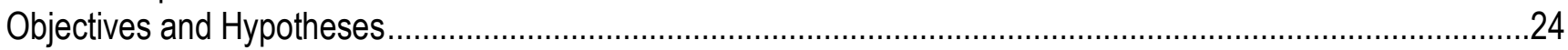

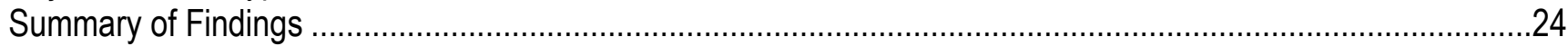

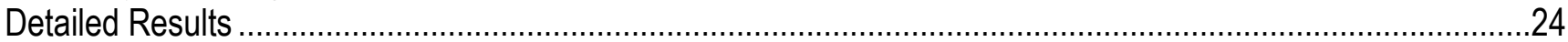

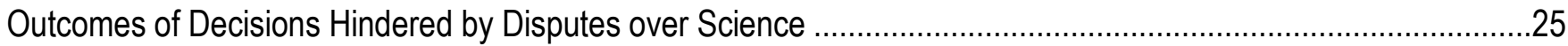

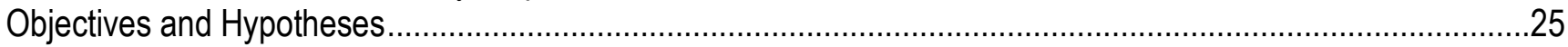

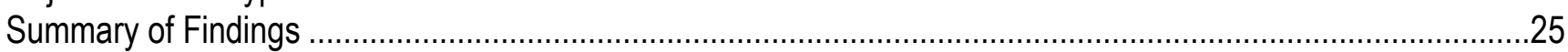

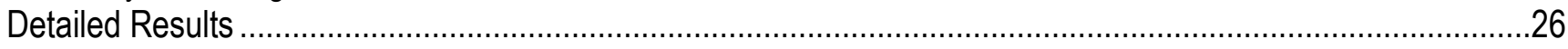

Experiences with Multiple Disputes over Science and (or) Dispute Resolution Method Types ................................27

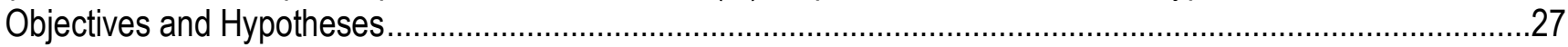

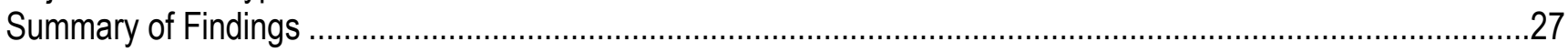

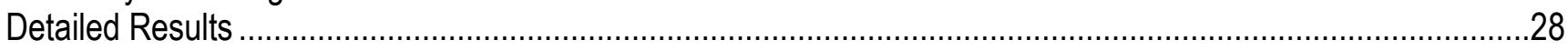

Evaluations of Dispute Resolution Resources for Reclamation Employees........................................................28

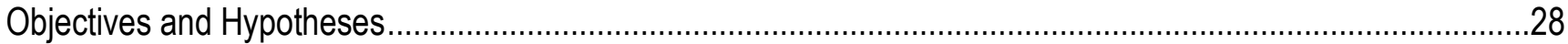

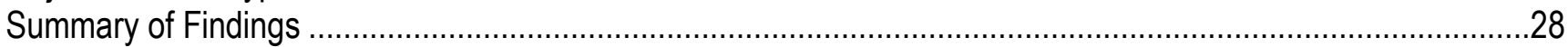

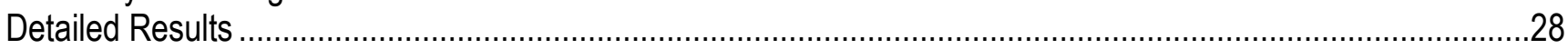

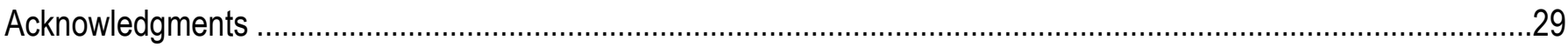

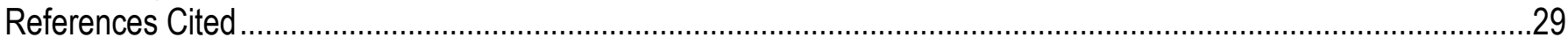

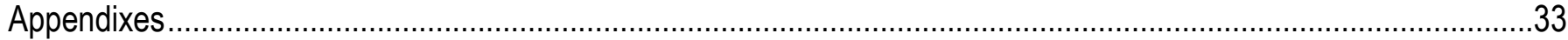

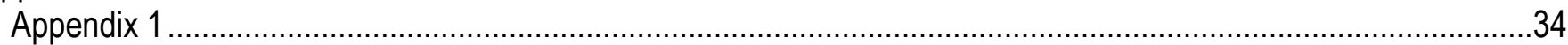

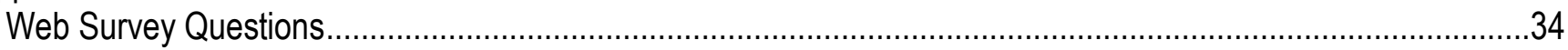

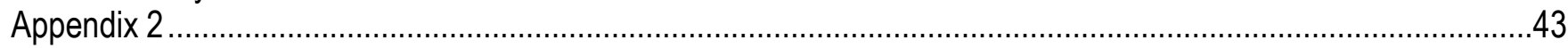

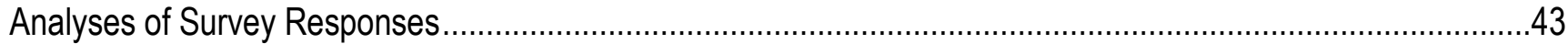

Respondents' Professional Background and Experience …………......................................................4

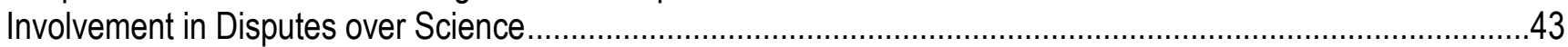

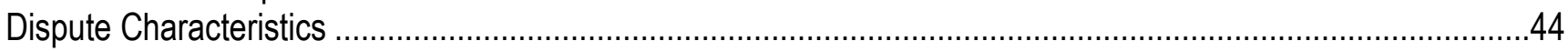

Dispute Resolution Methods.............................................................................................................4

Number of Issue and Party Types Involved in Dispute Versus Method Types Used..........................................44

Contested Factors in Disputes over Science....................................................................................45

Evaluations of Performance of Dispute Resolution Method Types...................................................................45

Dispute Resolution Professionals (DRPs) ......................................................................................45

Outcomes of Disputes over Science ……………………………..................................................46

Resolved Disputes over Science ......................................................................................................46

Outcomes of Decisions Hindered by Disputes over Science ........................................................................46

Experiences with Multiple Disputes over Science and (or) Dispute Resolution Methods ....................................47

Evaluations of Dispute Resolution Resources for Reclamation Employees ......................................................47

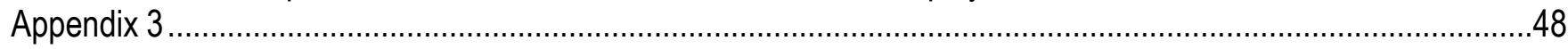

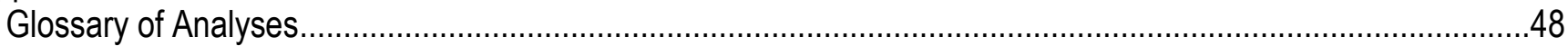

\section{Figures}

1. Proportion of respondents that selected each of the dispute resolution method types ................................. 15

2. Means and 95-percent confidence intervals for the number of non-Reclamation party types involved in disputes over science within each of the dispute resolution method categories ....................................... 16

3. Means and 95-percent confidence intervals (of the summated method performance scale for each of the dispute resolution method categories 
4. How respondents rated the perceived effects of dispute resolution professionals on dispute resolution processes on a 5-point "negative effect" to "positive effect" scale .....

5. Proportions and sample sizes of responses in each of the dispute outcome categories .............................2 23

6. Proportions and sample sizes of responses in each of the decision outcome categories............................2 26

7. Proportions and sample sizes for each of the categories of dispute outcomes within each of the decision outcome categories

\section{Tables}

1. Categories of dispute resolution methods defined by what parties and what activities they involve

2. Sample sizes and proportions of responses within each of the professional background and experience variables categories.

3. Sample sizes and proportion of responses that indicated that each scientific issue type had been involved in the dispute over science

4. Sample sizes and proportions of responses that indicated that each type of party was involved in the dispute over science

5. Sample sizes, medians, modes, proportions of responses within each category of the 5-point "not contested" to "highly contested" scale, and Friedman's mean rank values for each of the potentially contested factors in disputes over science

6. Sample sizes, Friedman's chi-square statistics, degrees of freedom, and Friedman's mean ranks for each of the eight performance statements that respondents rated on a 5-point "strongly disagree" to "strongly agree" scale for each of the dispute resolution method categories

7. Sample sizes and proportions of responses that had experience with dispute resolution professionals with each of the different affiliation types

8. Sample sizes, medians, modes, proportions of responses within each category of the 5-point "not useful" to "very useful" scale, and Friedman's mean rank values for each of the different potential resources intended to help Reclamation employees resolve disputes over science 


\title{
Disputes over Science and Dispute Resolution Approaches-A Survey of Bureau of Reclamation Employees
}

\author{
By Nina Burkardt and Emily W. Ruell
}

\section{Executive Summary}

A growing number of constituencies with different interests and values are competing for overallocated water resources in the Western United States (NRC, 2004). As a result, these users are increasingly challenging the decisions of the public agencies charged with managing Western water resources (NRC, 2004). Because they are the primary targets in litigation surrounding water management decisions, agency officials are motivated to pursue the best scientific information throughout the decision-making process so that their decisions are not later overturned (Adler and others, 2001). However, scientific studies pertaining to water resources in the West often provide uncertain or competing results or recommendations (NRC, 2004). As a result, science can become a source of disputes during decision-making processes. Disputes are defined here as "vocalized or articulated disagreements over what ought to be done" (Ozawa, 1996, p. 220). For example, a disagreement could focus on study design, methodology, scope, how findings should be used in a management decision, and so forth.

The Bureau of Reclamation (Reclamation) is one of the primary institutions that manages and allocates water resources in the West (Bowersox, 2000; Pisani, 2003). Consequently, Reclamation decision-making processes are frequently questioned by a variety of affected constituencies (NRC, 2004; Henry and Conrad, 2008). Disputes often erupt over the use of science in these decision-making processes when interests or objectives compete, which delay decisions and often continue long after decisions are made (Nie, 2003; Sabatier and others, 2005). Resolving these disputes over science during the decision-making processes should assist decision-makers in incorporating the best scientific judgment in natural resource management (Mazur, 1973; Ozawa and Susskind, 1985) and reduce the likelihood of later challenges.

Researchers at Reclamation and the U.S. Geological Survey conducted a literature review in 2010 of the different methods and approaches that have been used to resolve disputes over science during natural resource decision-making processes, particularly for water resources (Ruell and others, 2010). Published case studies have demonstrated that attempts to use dispute resolution methods are often unsuccessful at fully resolving the disputes over science, which likely prevents their broad application (Abrams and Berry, 1977; Roberts and others, 1984; Coglianese, 1999; Ehrmann and Stinson, 1999; Koontz and others, 2004; Ozawa, 2005; Sabatier, 2005; Quirk, 2005; Koontz and Thomas, 2006; Langfeldt, 2006; Lorie and Cardwell, 2006; van de Wetering and McKinney, 2006; Wagenet and Pfeffer, 2007; Hanemann and Dyckman, 2009). However, there are no empirical studies with large samples that have quantified how often these disputes over science arise, how often specific dispute resolution methods are used by managers to resolve these disputes, and how these methods have performed under a number of different circumstances. This information is needed in order to understand 
the real strengths and limitations of each dispute resolution method and help public officials choose the most effective approaches.

In spring 2011, we conducted a Web-based survey of Reclamation employees who were in scientific, technical, and managerial job categories to determine (1) which types of disputes over science are occurring and how common they are, (2) which approaches have been used by Reclamation to try to resolve these different types of disputes, (3) how useful Reclamation employees find these approaches at resolving these types of disputes, (4) the final outcomes of these disputes and the decision-making processes that were hindered by the disputes over science, and (5) the potential usefulness of several different types of dispute resolution resources that Reclamation could provide for employees that become involved in disputes over science. The survey questions can be found in appendix 1. Given that there may be variation across survey respondents that correspond with professional variation (Becher, 1994; Anderson and Bingham, 1997; von Meier, 1999), we also examined whether responses varied among Reclamation employees with different professional training, years of experience, or supervisory levels whenever sample sizes allowed.

\section{Main Findings}

- We found that the majority of the survey respondents were not in supervisory positions and had completed their primary professional training in engineering. Thirty percent of all respondents had worked for Reclamation for more than 20 years. Thus, a substantial proportion of survey respondents had likely worked at Reclamation for the majority of their careers. However, it is also possible that the employees that had worked at Reclamation for longer were more willing to complete the survey or were more likely to have been confronted with a dispute over science than those that had worked at Reclamation for less time.

- Twenty-five percent of respondents indicated that they had been involved in a dispute over science while working at Reclamation. This means that a substantial proportion of Reclamation employees in scientific, technical, and managerial positions have experienced disputes over science that impeded decision-making processes. Respondents that were trained in the biological sciences were more likely than other respondents to have been involved in a dispute over science, and those trained in administration and technical trades were less likely involved in a dispute. Respondents in supervisory positions at the time of the survey were more likely to have been involved in a dispute over science than nonsupervisors.

- Native species and species listed under the Endangered Species Act (ESA, 1973) were the most common issue types reported in employees' experience with disputes over science (roughly one out of every four responses). More than half of those reporting on a dispute over science indicated that the following entities were involved: non-Reclamation Federal entities (74 percent of responses), State entities ( 68 percent), water districts ( 71 percent), local entities ( 52 percent), and environmental groups (59 percent). The factors that respondents described as being the most contested in disputes over science were the validity of the inferences drawn from the science and how much uncertainty was in the science. The factor that was the least contested in disputes over science was the qualifications of the scientists that produced the science.

- More than nine out of every ten respondents who had been involved in a dispute over science reported experience with at least one of the dispute resolution methods categories. In one-third of the responses, the dispute resolution method selected was "direct discussions between scientists." The next most common dispute resolution method type was "public education, data sharing, and results dissemination." The dispute resolution method types that were the least common were "adaptive management" and "independent expert review." 
- "Active collaboration," "public education, data sharing, and results dissemination," and "adaptive management" generally involved a greater number of party types than the other method types, but did not involve a greater number of issue types. There were usually fewer party types involved if there was no method used to resolve the dispute than if a dispute resolution method had been used.

- All of the dispute resolution method types appeared to have similar strengths and weaknesses in resolving disputes over science. All method types were rated highest in how they were able to foster communication between parties about the science under dispute. All method types were also rated relatively high in their ability to increase the credibility of Reclamation's position on the science under dispute. Out of the eight different performance criteria, all method types were rated the lowest on their ability to resolve differences over the interpretation of the science, even though this factor was reported to be one of the most contested factors in disputes over science. In addition, all method types were also rated relatively low on how well they incentivized the parties to reach an agreement on the science under dispute. Despite this, all method types were rated somewhat higher for their ability to allow the process to move forward to a decision, regardless of whether agreement was reached about the science.

- The overall evaluation for each of the dispute resolution method types was neutral to somewhat positive, although there was a lot of room for improvement with every method type. Supervisors generally had more positive evaluations of the use of dispute resolution methods than nonsupervisors.

- The use of dispute resolution professionals appeared to be somewhat infrequent (reported by less than 17 percent of respondents). When they were used, respondents usually rated dispute resolution professionals as having a somewhat positive effect on the dispute over science.

- The majority of the disputes over science and the decision processes hindered by these disputes over science were still ongoing. The disputes that were resolved were most commonly resolved within Reclamation and at the level at which they originated. Respondents that had worked at Reclamation for less than five years were more likely than expected to indicate that the decision-making process was ongoing. Respondents that had worked at Reclamation for more than 10 years were more likely than expected to indicate that the decision had been made.

- There was a clear association between the outcome of the dispute over science and the outcome of the decision hindered by the dispute over science. In the majority of respondents' experiences, when the dispute was resolved, the decision was also made. The disputes that were still ongoing were almost always associated with decision processes that were still ongoing. Finally, when the dispute was not resolved and unlikely to be resolved, the decision was usually not made either.

- There was no indication that any of the dispute resolution method types resulted in substantially different outcomes in disputes over science than other types of disputes. Furthermore, there was also no apparent difference in the outcomes of disputes for which a dispute resolution method was attempted versus disputes for which no method was used. Similarly, there was no apparent difference between dispute resolution methods on the outcomes of the decisions that had been hindered by the dispute over science, and there was no apparent difference in the outcomes of decision processes when a dispute resolution method had been used versus those for which no method had been used. However, please note that the selection of the dispute resolution method types across disputes was not random; therefore, disputes for which no method type was used may have differed from the other disputes.

- Half of the respondents had experience with multiple dispute resolution method types in either the same or different disputes over science. Biological and physical scientists were more likely than 
respondents with other primary professional training backgrounds to have experience with multiple dispute resolution method types.

- Respondents rated a training class on resolving disputes over science and a bibliography on this subject as the most useful resources out of the potential resources that were suggested in the survey.

Although these survey results may be used to help predict which future decision-making processes are most likely to involve a dispute over science, which Reclamation employees are most likely to experience a dispute over science, and which aspects of the science under dispute are most likely going to be contested, they did not indicate that any dispute resolution method was more effective at resolving disputes over science than any other. Future research is needed to determine whether there are additional variables underlying these disputes that were not measured in this survey that may identify when dispute resolution methods are most effective, or whether resolving aspects of these disputes, such as differing interpretations of science, is very difficult or impossible regardless of the dispute resolution methods used.

\section{Background}

\section{Characteristics of Disputes over Science}

At the outset, resolving disputes over science usually requires identification of (1) the types of issues informed by the science that is under dispute, (2) the set of parties that are involved in the dispute, and (3) what aspects of the science are being disputed (Ruell and others, 2010). Ruell and others (2010) concluded that the most effective dispute resolution method likely depends on the type of dispute over science that arises. The dispute resolution methods that work well in some disputes may not work well in others because of these and other factors.

\section{Issues Involved}

Disputes over science can arise because of a number of different underlying issues. For example, when the use of a resource by one party automatically limits the use of the resource by another (that is, zero-sum resources), enduring disagreements often arise between competing parties over the use of science in decision-making for these resources (Quirk, 2005; Hanemann and Dyckman, 2009). In contrast, disputes over science may be less likely when resources are plentiful and may be relatively easy to resolve when they do arise. Disputes can also involve large, complex social and ecological systems where scientific uncertainty is unavoidably high (Johnson, 1999). These complex systems usually do not have straightforward technological solutions for improving management decisions (Johnson, 1999; Schmidtz, 2000; Nie, 2003). Furthermore, increasing recognition of the importance and complexity of ecological and social interactions has led to even greater uncertainty (Johnson, 1999; Ison and others, 2007). Yet, disputes may still arise in systems that are well studied and understood due to competing interests. However, the approaches required to resolve disputes involving well-studied systems may be different than systems where the science contains much uncertainty, regardless of the underlying cause of the dispute.

\section{Parties Involved}

How to effectively resolve disputes over the use of science may depend on the number and types of competing parties involved in the dispute. Types of parties can be defined by their differing beliefs, ideologies, groups, organizations, disciplines, communities, scientific training, or cultures. Some parties represent larger organizations or the "public interest," whereas others only represent themselves (van de 
Wetering and McKinney, 2006). Some parties are paid to participate; others must invest their own time and resources (van de Wetering and McKinney, 2006). Some representatives are willing and able to be flexible and modify their preferred decision alternatives, whereas others are unwilling or unable to be flexible because they have fixed commitments to their members, leaving no room for compromise (Roberts and others, 1984). There may also be subgroups within organizations that have different perspectives and come to different conclusions from the same science (von Meier, 1999).

Larger numbers of parties involved in a dispute can greatly increase the difficulty of organizing negotiations, particularly with ad hoc processes that do not have stable legal and administrative precedents (Quirk, 2005). Also, the parties involved in a dispute may change over time, which can greatly complicate attempts to incorporate revolving, frequently nonrepresentative groups of stakeholders in decision-making processes, particularly for time-consuming dispute resolution processes (Burkardt and others, 1995; Koontz and others, 2004; Quirk, 2005; Koehler and Koontz, 2008).

\section{The Science under Dispute}

There are many aspects of science itself that may cause a dispute among parties involved in a decision-making process. The following list is by no means exhaustive, but we argue that it touches on many of the likely issue areas behind disputes over science. First, parties may disagree on whether the existing science addressed all of the critical issues involved in the decision-making process. For example, the parties may disagree on whether or not the scientific studies measured all of the important variables. Second, parties may disagree on the appropriate quality of the data used in the decisionmaking process. The best science available for decision-making processes may range from anecdotal information to observational studies to peer-reviewed scientific experiments (Ruckelshaus and others, 2002; Ozawa, 2005; Henry and Conrad, 2008). Third, parties may disagree on the interpretations of the best available science as either too limited or too far-reaching (Quirk, 2005). Fourth, and along the same lines, parties may disagree on how much uncertainty there is in the science (Johnson 1999). Fifth, parties may disagree on whether more scientific studies are necessary before decision-making should take place. Sixth, parties may disagree on whether science is an appropriate basis for decision-making or whether decisions should be based on other factors. Although some parties may prefer that science is not required to justify an action, others may prefer to make decisions based primarily on the science available (Roeder, 2005; Stiftel and Scholz, 2005). Finally, parties may disagree on whether the scientists that produced the science were qualified, and by extension, whether the science itself is credible (Quirk, 2005).

\section{Dispute Resolution Methods}

Numerous methods for resolving disputes during decision-making processes have been proposed in the last several decades, and many of them have also been ground tested. Because some of these methods have been given multiple names by different academic or professional disciplines, overlap one another in methodology, or are simply too nebulous to be applied uniformly, we have developed the following broad categories or types of dispute resolution methods in table 1 from the literature on dispute resolution approaches (Ruell and others, 2010). These categories are differentiated by what activities and what parties the methods involve (table 1). 
Table 1. Categories of dispute resolution methods defined by what parties and what activities they involve. Dispute resolution method category Definition

Direct discussions between or among scientists

Processes that bring technical experts involved in a science dispute together to identify areas of agreement and disagreement, data needs and gaps, scientific protocols, and potential approaches to resolving technical disputes.

Independent expert review

One or more outside experts review the disputed science and reach conclusions regarding the weight of the evidence and the adequacy of the science.

Reclamation undertakes more science and analysis independently of the other parties

Reclamation undertakes additional studies or analyses in an effort to address concerns or conflicts.

Active collaboration in research and analysis

Outside parties involved in the dispute engage with Reclamation in collaborative science, jointly undertaking scientific training, hypothesis development, data collection, model building, or data analysis.

Public education, data sharing, and results dissemination

Any outreach activity designed to inform the public and stakeholders about the technical issues, existing data and science, and Reclamation's analysis of the information.

Uncertainties or differences over science in the management of water and related Adaptive management resources are addressed using planned programs of experimentation and adaptive decision-making based on scientific feedback.

\section{Defining Dispute Resolution}

Just as not all disputes over science are the same, dispute resolution processes may vary widely. Scholars have argued that there are many aspects to a dispute or the relationships between parties in a dispute that may improve even if the parties do not come to complete agreement (Roberts and others, 1984). Thus, scholars agree that a suite of effects should be used to evaluate successes and failures of different dispute resolution methods (Roberts and others, 1984; Ury and others, 1988; van de Wetering and McKinney, 2006). Most published case studies of dispute resolution methods have shown that these methods have mixed performance in resolving disputes (Abrams and Berry, 1977; Roberts and others, 1984; Coglianese, 1999; Ehrmann and Stinson, 1999; Koontz and others, 2004; Ozawa, 2005; Sabatier and others, 2005; Quirk, 2005; Koontz and Thomas, 2006; Langfeldt, 2006; Lorie and Cardwell, 2006; van de Wetering and McKinney, 2006; Wagenet and Pfeffer, 2007; Hanemann and Dyckman, 2009). For example, the use of a dispute resolution method may improve communications between parties about the science under dispute but may fail at getting parties to reach a common interpretation of that science.

The performance criteria evaluated in this study were identified from the literature on dispute resolution processes (Ruell and others, 2010). These criteria ranged from whether the resolution method improved relationships among parties in the dispute, regardless of whether the dispute was ultimately resolved, to the logistical feasibility of the method, to whether the method allowed the decision-making process that was delayed by the dispute to proceed to a decision. How well each method performs for each of these performance criteria may be more important to Reclamation in some situations than in others. We used respondents' evaluations of eight different performance measures to get a sense for how these resolution methods have performed relative to other resolution methods in different types of disputes over science. 


\section{Web Survey}

We conducted a Web survey of current Reclamation employees that could potentially have been involved in a dispute over science during a decision-making process that involved parties outside of Reclamation. We used the program Key Survey ${ }^{\mathrm{TM}}$ version 7.1 (WorldAPP, Braintree, Mass.) to administer the survey. Survey recipients were emailed a unique link (that is, a URL) that took them to a Web page that administered their survey. Recipients were allowed to leave and return to their saved survey at later dates until they submitted their survey.

Given that this online survey targeted Federal employees with advanced educational backgrounds and job-provided email and Internet access, we expected our response rate to be relatively high and comparable to response rates found for other professional and university populations (Yun and Trumbo, 2000; Shih and Fan, 2008). We did not conduct a nonresponse survey, because we expected that the representativeness of our sample would have minimal bias due to the relatively similar socioeconomic or educational status of the survey population of professionals (Yun and Trumbo, 2000).

The Web survey was structured to ensure that respondents would only answer questions about disputes over science in which they had some direct involvement, rather than disputes that they knew about secondhand. This was done to try to improve the accuracy of respondents' recounting of events and outcomes. Furthermore, we limited respondents to describing disputes over science that included both outside agencies or stakeholders and that were serious enough to impede a water-resource management decision, as these were the disputes in which Reclamation had the most interest in learning more about. The survey was divided into units composed of questions addressing different broad topics. Respondents were navigated through survey question units based on their answers to certain questions within each unit. The majority of the questions were closed-ended questions, which are the preferred format in surveys because they make responses comparable, and thus, easier to analyze using statistical analysis methods (Dillman and others, 2009). However, because the subjects of the survey were relatively complex, we included some open-ended questions that allowed the respondents to provide additional information on each part of the survey and on disputes over science in general. Whereas open-ended questions can increase the rate of incomplete surveys and can be difficult to analyze (Dillman and others, 2009), online surveys generally stimulate longer and more detailed comments than traditional mail-based surveys (Yun and Trumbo, 2000). With the exception of the question that asked respondents to describe the scientific issues that were under dispute, we did not analyze the responses to open-ended questions in this report.

\section{Topics of Survey Question Units}

\section{Unit 1}

The purpose of the first question unit was to determine whether or not respondents had ever been directly involved in a dispute over science, and if yes, then whether a dispute resolution method was used to try to resolve at least one of these disputes.

\section{Unit 2 (Beginning of Loop 1)}

This question was used to determine the categories of dispute resolution methods with which respondents have the most experience. 
Unit 3 (Beginning of Loops 2 and 3)

Respondents were asked to describe the nature of the most recent dispute over science in which they had been directly involved and that used a method within the dispute resolution method category that they had selected in unit 2 .

\section{Unit 4}

This question unit asked respondents to evaluate how well they thought the dispute resolution method performed in the dispute over science.

\section{Unit 5}

This unit of questions asked respondents if a dispute resolution professional (DRP) had been used in this dispute, and if yes, the effect of the DRP had on the dispute.

\section{Unit 6}

This unit of questions asked respondents to indicate the final outcome of the dispute over science. If the dispute was resolved, then respondents were asked to identify where the dispute was resolved and whether it escalated to a higher level of authority.

\section{Unit 7}

This unit of questions asked respondents to indicate the final outcome of the water-management decision that was hindered by the dispute and to provide any additional comments about this particular dispute over science.

\section{Unit 8}

This unit of questions asked respondents whether or not they had been involved in a dispute that had used one of the other dispute resolution methods from another category.

\section{Unit 9}

This unit of questions asked respondents to comment on disputes over science in general and to evaluate how useful they thought several potential dispute resolution resources would be for Reclamation employees.

Unit 10

The final unit contained questions on respondents' professional background and experience. Respondents were then directed to submit their survey.

\section{Survey Launch}

We selected 2,799 Reclamation employee email addresses to receive a survey invitation based on the job title categories they held on November 28, 2010, the date the email distribution list was compiled. These categories included all administrators, managers, specialists, technicians, scientists, economists, and engineers. Our selection of job title categories likely included many Reclamation employees who have not been involved in disputes over science, but we did not want to risk excluding a group that may have a different experience with these disputes over science than the others. The survey invitation email specifically asked that employees enter the survey and answer a few questions about their professional background even if they had not been involved with a dispute over science. Positions 
that clearly solely involved office administrative tasks were excluded because it was unlikely that these employees would be involved in these types of disputes.

On February 17, 2011, five days prior to the launch of the survey, a pre-notice email was sent by the Director of Reclamation's Research and Development Office to all survey recipients. This email encouraged employees to participate in the survey. On February 22, 2011, the invitation email was sent to all recipients with a link to the survey, which forwarded respondents to a Web site where the survey was hosted. Email links were user-specific so that the respondent could re-enter, view, and modify answers until the survey was finally submitted. Multiple submissions from the same link were prohibited. Follow-up reminder emails that included the original link were sent at approximately one (February 28, 2011), two (March 7, 2011), three (March 15, 2011), four (March 22, 2011), and five weeks (March 28, 2011) after the launch of the survey to the recipients that had not yet started or completed their survey. Previous studies have shown that the day of the week that the survey correspondence is received does not affect response rates, response time, or response quality (Shinn and others, 2007), and that the majority of responses are received within the first few days after invitation emails are sent (Yun and Trumbo, 2000; Shih and Fan, 2008). Nevertheless, we avoided sending survey emails on holidays or weekends so that the survey correspondence was less likely to be received during employees' vacations or buried within a pile of other emails received while employees were out of the office. We did not include any gift incentives for recipients, because Federal employees are prohibited from accepting them, and they do not appear to significantly increase response rates for electronic surveys (Yun and Trumbo, 2000; Baruch and Holtom, 2008).

\section{Study Objectives and Results}

There were 1,645 respondents that completed their surveys and 100 that started but did not complete their surveys. Of those respondents that did not start their survey, there were 1,044 that were considered implicit refusals and 10 that were verified as noncontacts for the duration of the survey based on the content of their automated email replies. Thus, our calculated minimum response rate was 59 percent. This response rate was high relative to other electronic surveys that have been conducted (Yun and Trumbo, 2000) and was higher than the average response rates for both Web surveys (34 percent) and mail surveys (45 percent) in the meta-analysis conducted by Shih and Fan (2008).

\section{Respondents' Professional Background and Experience}

\section{Objectives and Hypotheses}

The objective was to determine the professional background and experience of respondents, including primary professional training, supervisory experience, and the number of years respondents had worked for Reclamation. We did not have any predictions regarding the professional background and experience of respondents.

\section{Summary of Findings}

- Engineering was the most common primary professional training of respondents, followed by administration (including contracts and realty), and biological sciences.

- The majority of respondents were not in supervisory roles at the time of the survey. 
- Approximately one-third of respondents had been employed for five years or less at Reclamation, but an almost equal number had worked there more than 20 years. However, the second-most common category of years working at Reclamation selected by respondents was over 20 years.

\section{Detailed Results}

The number and percentage of respondents within each category of the professional background and experience variables are presented in table 2 . Some of the categories for the primary professional training were not in the original survey but were coded from "other, please specify" responses or combined (see appendix 2). Please note that these statistics do not represent all Reclamation employees at the time of the survey but only the Reclamation employees within the job categories that were selected to receive the survey.

Table 2. Sample sizes and proportions of responses within each of the professional background and experience variables categories.

\begin{tabular}{|c|c|c|}
\hline Professional background and demographic variables and categories & $\begin{array}{l}\text { Number of } \\
\text { responses }\end{array}$ & Percent ${ }^{1}$ \\
\hline \multicolumn{3}{|l|}{ Supervisory position $(n=1,633)$} \\
\hline No & 1,304 & 80 \\
\hline Yes & 329 & 20 \\
\hline \multicolumn{3}{|l|}{ Primary professional training $(n=1,637)$} \\
\hline Engineering & 714 & 44 \\
\hline Administration/Business/Contracts/Realty & 358 & 22 \\
\hline Biological sciences & 199 & 12 \\
\hline Physical sciences & 149 & 9 \\
\hline Social sciences & 113 & 7 \\
\hline Technical trades/Visitor services & 60 & 4 \\
\hline Law & 22 & 1 \\
\hline Other & 10 & 1 \\
\hline Architecture & 6 & 0 \\
\hline Computer science & 4 & 0 \\
\hline Law enforcement & 2 & 0 \\
\hline \multicolumn{3}{|l|}{ Years worked at Reclamation at time of survey $(n=1,637)$} \\
\hline $0-5$ years & 524 & 32 \\
\hline $6-10$ years & 302 & 18 \\
\hline $11-15$ years & 191 & 12 \\
\hline $16-20$ years & 125 & 8 \\
\hline$>20$ years & 495 & 30 \\
\hline
\end{tabular}

${ }^{1}$ Percentage within each category within each variable.

A generalized linear model (GZLM) for respondents' number of years worked at Reclamation ( $0-5$ years, $6-10$ years, $11-15$ years, $16-20$ years, $>20$ years) revealed that the predicted main effect of primary professional training was significant (Wald $\left.\chi^{2}(10, n=1,627)=32.85, p<0.001\right)$, and the predicted main effect of supervisors was significant (Wald $\chi^{2}(1, n=1627)=21.63, p<0.001$ ). It is possible that there were gender differences in the professional training and supervisory experience 
variables that may have confounded the associations found in the analysis above and elsewhere in this report, but we were not able to ask respondents to indicate their gender in this survey.

\section{Involvement in Disputes over Science}

\section{Objectives and Hypotheses}

Our main objectives were to assess (1) how common it has been for Reclamation employees in scientific and technical positions to have direct experience with one or more disputes over science and (2) whether certain types of employees in scientific and technical positions in Reclamation have been more likely to be involved in disputes over science than others.

Specifically, we predicted that the respondents trained in "biological sciences" would have been more likely to be involved in disputes than others because they would be involved in conducting scientific studies for, or implementing, environmental laws, such as the Endangered Species Act (ESA, 1973) and the National Environmental Policy Act (NEPA, 1969). These laws explicitly require that decision-making processes utilize the best available science and involve other agencies and the interested public. In contrast, we expected that respondents trained in "administration, business, realty, and contracts" and in "technical trades and visitor services" would be less likely to have been involved in disputes over science than the other professional training categories because they would be less likely to be involved in implementing laws that require science to be the basis of decisions.

We also predicted that the respondents in supervisory positions would be more likely to have been involved in a dispute over science at some point than nonsupervisors because supervisors likely have an increased exposure to disputes via their supervisees.

Finally, we predicted that the respondents that had worked for Reclamation for a greater period of time would have been exposed to more situations or decisions that would potentially result in a dispute over science.

\section{Summary of Findings}

- Roughly one out of every four respondents had been involved in a dispute over science. Again, this does not represent the proportion of all Reclamation employees that have experienced a dispute over science but rather the proportion of Reclamation employees within the job categories that were selected to receive the survey.

- Respondents with primary professional training in "biological sciences" were more likely to have been involved in a dispute than respondents with other types of primary professional training. Respondents with professional training in "administration/business/realty/contracts" and "technical trades/visitor services" were less likely to have been involved in a dispute than respondents with other types of professional training.

- Respondents in supervisory positions were more likely to have been involved in a dispute over science than nonsupervisors.

- We found that the more years that a respondent had worked for Reclamation, the higher their probability of having been involved in a dispute over science.

\section{Detailed Results}

Respondents to all complete and incomplete surveys $(n=1,745)$ answered the first mandatory survey question, which asked whether or not respondents had ever been involved in a dispute over 
science. From these surveys, 25 percent of the respondents $(n=438)$ indicated that they had been involved in a dispute over science that included parties outside of Reclamation.

The GZLM revealed that the predicted main effect of primary professional training was significant (Wald $\left.\chi^{2}(10, n=1,627)=99.63, p<0.001\right)$. Post hoc $z$ tests of the contingency table of involvement in a dispute over science by primary professional training (Pearson's $\chi^{2}(10, n=1,637)=$ $128.04, p<0.001$ ) revealed that respondents with professional training in "biological sciences" were more likely to have been involved in a dispute than respondents with other types of professional training, and respondents with professional training in "administration/business/realty/contracts" and "technical trades/visitor services" were less likely to have been involved in a dispute than respondents with other types of professional training. The GZLM also revealed that the predicted main effect of supervisors was significant when taking into account primary professional training (Wald $\chi^{2}(1, n=$ $1,627)=28.87, p<0.001)$. Of the 329 respondents that were supervisors, 29 percent $(n=95)$ indicated that they had been involved in a dispute over science, and only 17 percent $(n=215)$ of the 1,304 nonsupervisors had been involved in a dispute over science. Finally, the GZLM revealed that the predicted main effect of the number of years respondents had worked at Reclamation was significant when taking into account both primary professional training and supervisory position (Wald $\chi^{2}(4, n=$ $1,627)=18.35, p=0.001)$.

\section{Dispute Characteristics}

\section{Objectives and Hypotheses}

The main objective was to measure the scope of the disputes over science in which Reclamation employees have been involved, including both the number and types of issues that commonly underlie disputes over science, and the different types of parties outside of Reclamation that were usually involved in the disputes.

We predicted that native and endangered species would be the most common issue types underlying disputes over science because the requirements of the ESA (1973) and NEPA (1969) often compete with interests of other parties.

We predicted that other Federal agencies, water districts, and State agencies would be the outside parties most frequently involved in respondents' disputes due to the requirements of the ESA (1973) and NEPA (1969).

\section{Summary of Findings}

- The large majority of respondents (81 percent) described only one type of issue. Fewer respondents (16 percent) reported two issue types, and fewer still reported three or four issue types ( $<2$ percent).

- The most frequent types of issues reported in the responses included native species (25 percent; including all aquatic and terrestrial plant and animal species), endangered or threatened species protected under the ESA (1973) (23 percent), surface-water measurements (15 percent), and natural hazard risks (11 percent). The least frequent types of issues reported by respondents in less than 1 percent of the responses were Native American rights, economic analyses, climate change effects, aquaculture, and dam removal.

- The disputes over science described by respondents usually involved multiple types of parties outside of Reclamation. In the majority of responses, Federal entities, water districts, State entities, environmental groups, and local entities were involved in the disputes over science. 


\section{Detailed Results}

Out of the 100 incomplete surveys, 29 respondents had at least completed questions from units 1-7 (they had completed loop 1 of the survey) for a dispute over science. Therefore, these responses were considered complete enough and were included with the completed surveys in further analyses on the characteristics of the disputes and respondents' evaluation of the different dispute resolution methods.

Out of the 347 respondents that had experience with disputes over science, 83 percent $(n=288)$ reported a range of one to four issue types. The large majority, 81 percent of respondents $(n=234)$, described only one issue type. However, many respondents reported that multiple issue types were involved in the dispute: 16 percent $(n=46)$ of respondents reported two issue types, 1 percent $(n=4)$ of respondents reported three issue types, and 1 percent $(n=4)$ of respondents reported four issue types. The number and percentage of respondents that reported each issue type is presented in table 3 .

Table 3. Sample sizes and proportion of responses that indicated that each scientific issue type had been involved in the dispute over science (check all that apply).

\begin{tabular}{|c|c|c|}
\hline Issue type(s) underlying disputes over science ${ }^{1}$ & $\begin{array}{l}\text { Number of } \\
\text { responses }\end{array}$ & Percent $^{2}$ \\
\hline Native species & 72 & 25 \\
\hline Endangered species & 65 & 23 \\
\hline Surface-water aspects (storage, flow, quality, and so forth) & 44 & 15 \\
\hline Natural hazard risk (seismic activity, drought, flooding, and so forth) & 32 & 11 \\
\hline Geomorphology & 25 & 9 \\
\hline Agriculture & 19 & 7 \\
\hline Water rights & 16 & 6 \\
\hline Non-native species & 14 & 5 \\
\hline Materials engineering (quality, durability, and so forth of materials used) & 14 & 5 \\
\hline Human health risk due to toxicity or disease & 12 & 4 \\
\hline Groundwater aspects (levels, quality, connections, and so forth) & 11 & 4 \\
\hline Cultural resources & 6 & 2 \\
\hline Hydropower & 4 & 1 \\
\hline Recreation & 4 & 1 \\
\hline Desalinization plants & 4 & 1 \\
\hline Economic analyses & 3 & 1 \\
\hline Climate change effects & 3 & 1 \\
\hline Native American rights & 2 & 1 \\
\hline Aquaculture & 2 & 1 \\
\hline Dam removal & 2 & 1 \\
\hline
\end{tabular}

${ }^{1}$ Responses to an open-ended question on the issues underlying the dispute were coded into general categories of issues by authors NB and ER. Many disputes involved more than one issue type (range of one to four issue types).

${ }^{2}$ The percentage of responses $(n=288)$ within each issue type. 
Multiple types of parties outside of Reclamation were usually involved in disputes over science $(M=4.73, S D=2.48$, range $=1-11$ party types $)$. The number and percentage of respondents that reported each party type is presented in table 4.

Table 4. Sample sizes and proportions of responses that indicated that each type of party was involved in the dispute over science (check all that apply).

\begin{tabular}{lcc}
\hline Outside party type(s) involved in disputes over science ${ }^{1}$ & $\begin{array}{c}\text { Number of }_{\text {responses }} \\
\text { Federal entity }\end{array}$ & Percent $^{2}$ \\
Water district & 254 & 74 \\
State entity & 241 & 71 \\
Environmental interest group & 231 & 68 \\
Local entity & 202 & 59 \\
Tribal entity & 178 & 52 \\
Business entity & 111 & 33 \\
Individual citizens & 100 & 29 \\
Academia & 92 & 27 \\
Recreation interest group & 90 & 26 \\
International entity & 84 & 25 \\
Elected officials & 27 & 8 \\
\hline
\end{tabular}

${ }^{1}$ Respondents were instructed to select all non-Reclamation party types that were involved in the dispute. Most disputes included multiple party types (range $1-11$ party types).

${ }^{2}$ The percentage of responses $(n=342)$ within each party type.

\section{Dispute Resolution Methods}

\section{Objectives and Hypotheses}

The primary objectives were to determine (1) whether the use of dispute resolution methods was common in disputes over science involving Reclamation employees and (2) which of the methods types were the most common in Reclamation employees experiences. We did not have any a priori predictions regarding the use of different dispute resolution method types in Reclamation.

\section{Summary of Findings}

- The majority of respondents with direct experience with disputes over science indicated that some sort of dispute resolution method had been used to try to resolve the dispute over science.

- The most common dispute resolution method categories selected by respondents were "direct discussion between scientists" and "public education, data sharing, and results dissemination."

\section{Detailed Results}

From the group of respondents that had been involved in a dispute over science and had completed question units 1-7 $(n=347), 324$ (93 percent) had experience with the use of at least one of the dispute resolution methods from the categories listed, and 23 ( 7 percent) had no experience with any 
of the dispute resolution method categories. None of the respondents indicated that they had used a method that did not fall into one of the six categories provided. The dispute resolution method category that respondents had the most experience with was "direct discussion between scientists" followed by "public education, data sharing, and results dissemination" (fig. 1). The method categories that respondents had the least experience with were "adaptive management" and "independent expert review."

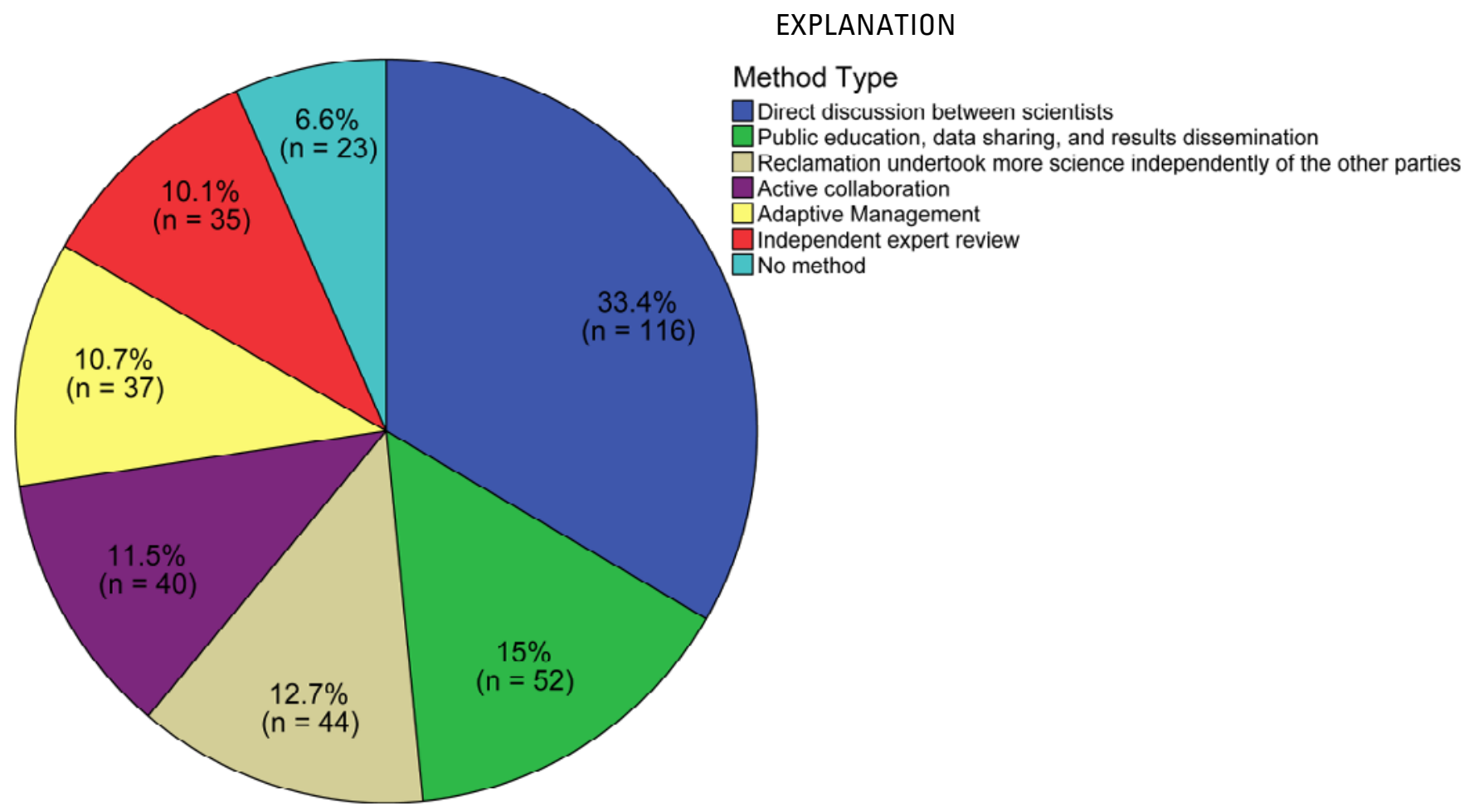

Figure 1. Proportion of respondents that selected each of the dispute resolution method types.

\section{Number of Issue and Party Types Involved in Dispute Versus Method Types Used}

\section{Objectives and Hypotheses}

The primary objectives were to determine whether certain dispute resolution method types were more likely to involve (1) fewer or more issue types or (2) fewer or more party types than the others.

We predicted that dispute resolution method types that generally require agencies to include stakeholders and interest groups in their implementation, such as "active collaboration," "public education, data sharing, and results dissemination," and "adaptive management" (Ruell and others, 2010), were more likely to be associated with disputes that involved more issue types and party types outside of Reclamation than method types that did not include outside parties, such as "direct discussion between scientists" and "Reclamation undertakes more science independently of the other parties."

We predicted that disputes over science for which no dispute resolution method was used would have the smallest mean number of outside party types involved because disputes that involved larger numbers of outside parties would be more likely to have one or more parties call for or initiate some sort of dispute resolution process. 


\section{Summary of Findings}

- There was no apparent association between the number of issue types involved and the dispute resolution method type that was used to resolve the disputes over science.

- In general, dispute resolution method types that usually require agencies to include stakeholders and interest groups in the dispute resolution process had a larger mean number of party types outside of Reclamation involved. In particular, the method type "adaptive management" was associated with the largest mean number of outside party types.

- Disputes over science for which no method was used to resolve the dispute had a smaller mean number of party types outside of Reclamation involved in the dispute than those for which a dispute resolution method had been attempted.

\section{Detailed Results}

The numbers of issue types that were involved in respondents' experiences with disputes over science did not significantly differ between the dispute resolution method types, contrary to our expectation (Pearson's $\left.\chi^{2}(18, n=286)=13.47, p=0.763\right)$.

The mean number of party types that were involved in the disputes did vary significantly among the different types of dispute resolution methods used $(F(6,335)=3.832, p=0.001)$. The mean number of party types involved for "adaptive management" was significantly higher than the mean for disputes with no dispute resolution method, "direct discussion between scientists," and "Reclamation undertakes more science independently of the other parties" in Tukey post-hoc tests with $p<0.05$ (fig. 2).

Furthermore, respondents that indicated that no method was used to resolve the dispute tended to be involved in disputes with a significantly smaller mean number of parties involved $(M=3.57$, $S D=1.83)$ than respondents with experience with a dispute resolution method $(M=4.80, S D=2.50$; $t(340)=-2.06, p=0.040)$.

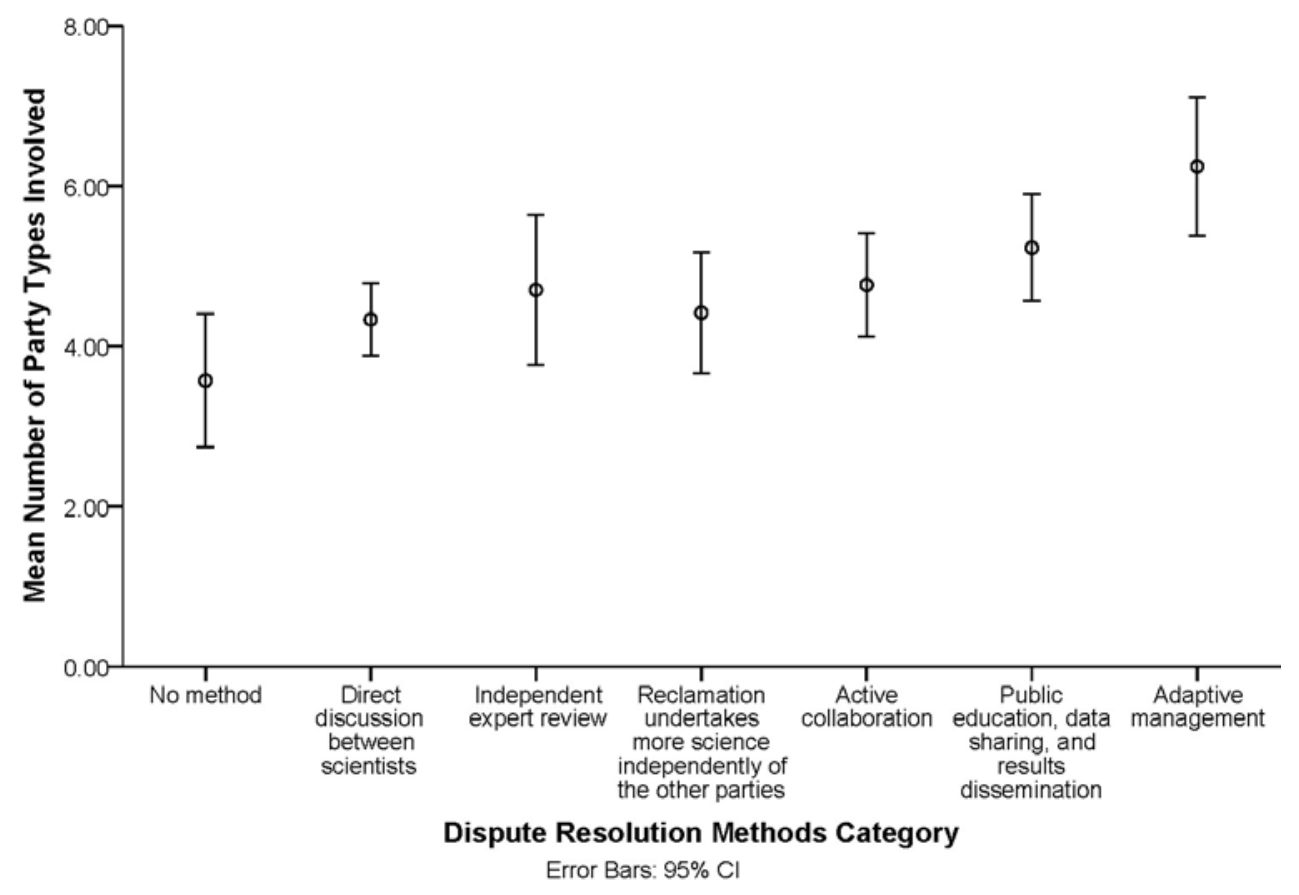

Figure 2. Means and 95-percent confidence intervals $(\mathrm{Cl})$ for the number of non-Reclamation party types involved in disputes over science within each of the dispute resolution method categories. 


\section{Contested Factors in Dispute over Science}

\section{Objectives and Hypotheses}

The main objectives were (1) to determine what aspects or characteristics of science were most contested between parties in the disputes over science and (2) whether the reported levels of contestation of any of the factors in the dispute differed across the dispute resolution method types. We did not have any a priori predictions on the relative contestation of different characteristics of the disputes over science experienced by Reclamation employees.

\section{Summary of Findings}

- The four factors that respondents rated the highest on the 5-point "not contested" to "highly contested" scale were "the inference(s) drawn from the science," followed by "the level of uncertainty in the science," "whether or not the existing science addressed the critical issues," and "the quality of the data used." More than 50 percent of respondents rated these four factors as either a value of 4 or 5 (contested to highly contested). The factor that respondents rated the lowest on the scale was "the qualifications of the scientists who produced the science."

- The dispute resolution method type used did not appear to be associated with the degree to which any of the seven factors were contested.

\section{Detailed Results}

There was a significant difference in how respondents rated each of the seven potentially contested factors when describing their disputes over science (Friedman's $\chi^{2}(6, n=264)=262.44, p$ $<0.001$ excluding responses that selected "I don't know" or "not applicable" for any of the seven factors; table 5). A small percentage of the respondents gave "not applicable" or "I don't know" answers for each of the factors (range $2-5$ percent of respondents).

The distribution of respondents' ratings did not significantly differ among the dispute resolution method categories for any of the seven factors (the Kruskall-Wallis one-way ANOVA (analysis of variance) tests were not significant with $p \geq 0.161$; table 5).

In addition to the seven potentially contested factors listed in the survey, respondents were given the option of adding an "other, please specify" response. These additional options were not evaluated by respondents on the "not contested" to "highly contested" scale and are not included in table 5 or in the analysis.

\section{Evaluations of Performance of Dispute Resolution Method Types}

\section{Objectives and Hypotheses}

The main objectives were to determine (1) which aspects of the disputes over science each of the dispute resolution methods were the most or the least successful at resolving, (2) whether any of the dispute resolution method categories were better or worse at resolving disputes over science than the others, (3) whether differences in respondents' experiences were associated with their professional background and experience. We did not have any a priori predictions for these three objectives. 
Table 5. Sample sizes, medians, modes, proportions of responses within each category of the 5-point "not contested" to "highly contested" scale, and Friedman's mean rank values for each of the potentially contested factors in disputes over science.

\begin{tabular}{|c|c|c|c|c|c|c|c|c|c|}
\hline \multirow[t]{2}{*}{$\begin{array}{l}\text { Potentially contested factors in } \\
\text { disputes over science }\end{array}$} & \multirow[t]{2}{*}{$\begin{array}{l}\text { Number of } \\
\text { responses }^{1}\end{array}$} & \multirow[t]{2}{*}{ Median } & \multirow[t]{2}{*}{ Mode } & \multicolumn{5}{|c|}{$\begin{array}{c}\text { Scale } \\
\text { "not contested" to "highly } \\
\text { contested" }\end{array}$} & \multirow[t]{2}{*}{$\begin{array}{l}\text { Freidman's } \\
\text { mean rank }\end{array}$} \\
\hline & & & & 1 & 2 & 3 & 4 & 5 & \\
\hline $\begin{array}{l}\text { 1. Whether or not the existing } \\
\text { science addressed the critical } \\
\text { issues }\end{array}$ & 315 & 4 & 4 & $11 \%$ & $12 \%$ & $18 \%$ & $33 \%$ & $26 \%$ & 4.40 \\
\hline 2. The quality of the data used & 323 & 4 & 4 & $11 \%$ & $11 \%$ & $26 \%$ & $33 \%$ & $20 \%$ & 4.18 \\
\hline $\begin{array}{l}\text { 3. The inference(s) drawn from } \\
\text { the science }\end{array}$ & 321 & 4 & 4 & $5 \%$ & $7 \%$ & $17 \%$ & $39 \%$ & $32 \%$ & 5.07 \\
\hline $\begin{array}{l}\text { 4. The level of uncertainty in } \\
\text { the science }\end{array}$ & 322 & 4 & 4 & $7 \%$ & $10 \%$ & $25 \%$ & $36 \%$ & $22 \%$ & 4.41 \\
\hline $\begin{array}{l}\text { 5. The need for additional } \\
\text { scientific investigation }\end{array}$ & 324 & 3 & 4 & $21 \%$ & $14 \%$ & $19 \%$ & $30 \%$ & $17 \%$ & 3.76 \\
\hline $\begin{array}{l}\text { 6. Whether or not science } \\
\text { should be the basis for the } \\
\text { management decision }\end{array}$ & 315 & 3 & 1 & $28 \%$ & $16 \%$ & $18 \%$ & $17 \%$ & $21 \%$ & 3.47 \\
\hline $\begin{array}{l}\text { 7. The qualifications of the } \\
\text { scientists who produced the } \\
\text { science }\end{array}$ & 311 & 2 & 1 & $34 \%$ & $24 \%$ & $19 \%$ & $14 \%$ & $9 \%$ & 2.70 \\
\hline
\end{tabular}

${ }^{1}$ The number of responses for each factor and the calculated medians, modes, and percentages within each category in the 5point not contested to highly contested scale do not include the "not applicable" and "I don't know" responses for that factor.

${ }^{2}$ Calculated from the responses $(n=264)$ that did not select "I don't know" or "not applicable" for any of the seven factors.

\section{Summary of Findings}

- There were significant differences in respondents' ratings across the eight different performance statements for all of the method types. Furthermore, ratings for each of the eight statements remained fairly consistent across all of the method types. Across method types, the resolution statements to which respondents gave the highest agreement scores for all of the method types were "the method fostered communication between the parties about the scientific issues," and "the method increased the scientific credibility of Reclamation's position." The resolution statements to which respondents gave the lowest agreement scores for almost all of the method types were "the method resolved differences over the interpretation of the science," and "the method created incentives to reach agreement on the dispute over science."

- There was no dispute resolution method category that appeared to resolve disputes substantially better or worse than any others, including the category "no method." However, please note that the selection of the dispute resolution method types across disputes was not random; therefore, the disputes may have differed in some way across groups.

- For the most part, the evaluations of dispute resolution method types were slightly positive.

- Respondents' evaluations of the dispute resolution methods did not vary by primary professional training, supervisory position, or the number of years that respondents had worked at Reclamation. 


\section{Detailed Results}

The results of the analyses of respondents' ratings for each of the performance statements are presented in table 6 .

Table 6. Sample sizes, Friedman's chi-square statistics, degrees of freedom (d.f.), and Friedman's mean ranks for each of the eight performance statements (that is, Likert items) that respondents rated on a 5-point "strongly disagree" to "strongly agree" scale for each of the dispute resolution method categories.

\begin{tabular}{|c|c|c|c|c|c|c|c|c|c|c|c|c|}
\hline \multirow{2}{*}{$\begin{array}{l}\text { Dispute resolution } \\
\text { method type used }\end{array}$} & \multirow{2}{*}{$\begin{array}{l}\text { Number of } \\
\text { responses }^{1}\end{array}$} & \multirow{2}{*}{$\begin{array}{l}\text { Friedman's } \\
\text { chi-square }\end{array}$} & \multirow{2}{*}{ d.f. } & \multirow{2}{*}{$p$-value } & \multicolumn{8}{|c|}{ Friedman's mean rank for performance statements $1-8^{2}$} \\
\hline & & & & & 1 & 2 & 3 & 4 & 5 & 6 & 7 & 8 \\
\hline $\begin{array}{l}\text { Direct discussion } \\
\text { between or among } \\
\text { scientists }\end{array}$ & 113 & 121.77 & 7 & $<0.001$ & 6.27 & 3.52 & 3.78 & 4.97 & 4.27 & 4.67 & 4.22 & 4.29 \\
\hline $\begin{array}{l}\text { Independent expert } \\
\text { review }\end{array}$ & 33 & 36.86 & 7 & $<0.001$ & 5.59 & 3.89 & 3.29 & 5.65 & 4.17 & 4.24 & 4.35 & 4.82 \\
\hline $\begin{array}{l}\text { Reclamation } \\
\text { undertakes more } \\
\text { science and } \\
\text { analysis } \\
\text { independently of } \\
\text { the other parties }\end{array}$ & 42 & 46.00 & 7 & $<0.001$ & 5.75 & 3.71 & 3.90 & 5.69 & 3.58 & 3.98 & 4.58 & 4.80 \\
\hline $\begin{array}{l}\text { Active } \\
\text { collaboration in } \\
\text { research and } \\
\text { analysis }\end{array}$ & 37 & 41.20 & 7 & $<0.001$ & 6.38 & 3.81 & 3.74 & 4.89 & 3.84 & 4.07 & 4.55 & 4.72 \\
\hline $\begin{array}{l}\text { Public education, } \\
\text { data sharing, and } \\
\text { results } \\
\text { dissemination }\end{array}$ & 47 & 30.45 & 7 & $<0.001$ & 5.64 & 3.46 & 3.96 & 4.72 & 4.68 & 4.48 & 4.69 & 4.37 \\
\hline $\begin{array}{l}\text { Adaptive } \\
\text { management }\end{array}$ & 34 & 32.34 & 7 & $<0.001$ & 5.82 & 3.65 & 3.53 & 4.97 & 4.10 & 4.07 & 4.96 & 4.90 \\
\hline
\end{tabular}

${ }^{1}$ Does not include responses that selected "I don't know" or "not applicable" for any of the eight resolution statements.

${ }^{2}$ Statement 1: The method fostered communication about scientific issues.

Statement 2: The method resolved differences over interpretation of the scientific results.

Statement 3: The method created incentives to reach agreement on the dispute over science.

Statement 4: The resolution method increased the scientific credibility of Reclamation's position.

Statement 5: The time required for this method was reasonable for Reclamation.

Statement 6: The money required for this method was reasonable for Reclamation.

Statement 7: The method made it possible to move forward in the absence of agreement over the science.

Statement 8: The method helped the process proceed to the decision delayed by the dispute over science. 
The mean value for the summated performance scale was significantly greater than zero (the 95percent confidence intervals did not overlap zero) for all of the method categories except "Reclamation undertakes more science independently of the other parties" and "adaptive management" (fig. 3). The means for the summated performance scale did not significantly differ across the dispute resolution method categories $(F(5,300)=0.381, p=0.862)$.

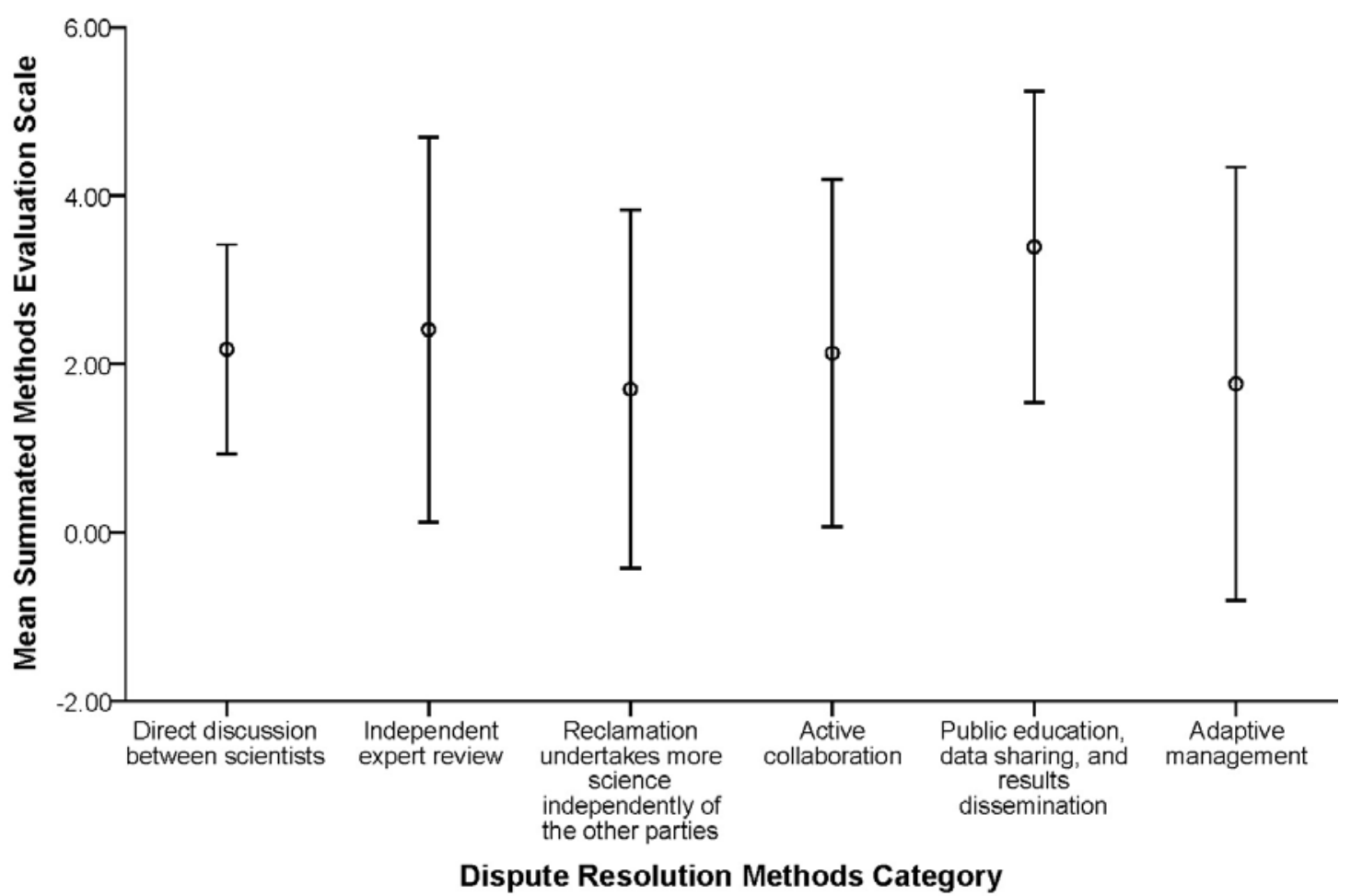

Error Bars: $95 \% \mathrm{Cl}$

Figure 3. Means and 95-percent confidence intervals $(\mathrm{Cl})$ of the summated method performance scale (an eightitem Likert scale with Cronbach's alpha $=0.86$ ) for each of the dispute resolution method categories. Survey recipients were asked to rate the dispute resolution method used for eight different performance statements that evaluated whether the dispute resolution method improved different aspects of the dispute over science using a 5-point scale ranging from -2 ("strongly disagree") to +2 ("strongly agree"). The highest and lowest possible summated scores for these eight Likert items were +16 and -16 , respectively.

The four-way ANOVA for the summated method performance scale across all methods revealed that the main effect of primary professional training was not significant $(F(4,268)=0.165, p=$ $0.956)$, the main effect of supervisory position was not significant $(F(1,268)=2.83, p=0.094)$, and the main effect of number of years worked at Reclamation was not significant $(F(4,268)=2.25, p=0.064)$.

\section{Dispute Resolution Professionals (DRPs)}

\section{Objectives and Hypotheses}

The main objectives were to determine (1) how often DRPs were utilized in the disputes over science in which Reclamation employees have been involved, (2) the most common affiliations of these 
DRPs, (3) whether the DRPs were helpful in resolving disputes over science, (4) whether DRPs were utilized more or less frequently with some of the dispute resolution method categories than others, and (5) whether DRPs were rated as having a more positive or negative effect when they were utilized in conjunction with the different dispute resolution method categories.

We predicted that respondents that had experience with "public education, data sharing, and results dissemination," "active collaboration," and "adaptive management" would be more likely to also have experience with the use of a DRP. The implementation of either method type typically requires the involvement of multiple types of parties (Ruell and others, 2010); thus, we predicted that there would be a greater likelihood that a negotiator or mediator would be involved because there were more parties involved in these disputes that could make the request for one.

\section{Summary of Findings}

- The use of DRPs was not common in the disputes over science in which Reclamation employees had been involved. Less than 17 percent of respondents described disputes that involved a DRP.

- DRPs were most frequently affiliated with an independent consulting firm, followed by another Federal agency.

- In respondents' experiences, DRPs mostly had a neutral or a somewhat positive effect on the resolution process for disputes over science.

- As we predicted, DRPs were more likely to be involved in disputes where either of the method categories "public education, data sharing, and results dissemination" and "adaptive management" were also used than in conjunction with the other method types. Contrary to our prediction, "active collaboration" was not more likely to involve a DRP than the other method categories.

- Respondents' ratings of the effect of the DRP on the dispute resolution process did not significantly differ across the different dispute resolution method categories.

\section{Detailed Results}

There were 17 percent $(n=57)$ of respondents that described disputes over science for which a DRP was used, 75 percent $(n=259)$ that described disputes that did not include a DRP, and 8 percent $(n$ $=29$ ) that did not know if a DRP had been used in the dispute. The number and percentage of respondents that indicated the affiliation type of the DRP involved in the dispute over science are presented in table 7 .

Table 7. Sample sizes and proportions of responses that had experience with dispute resolution professionals with each of the different affiliation types.

\begin{tabular}{lcc}
\hline Dispute resolution professional affiliation type & $\begin{array}{c}\text { Number of } \\
\text { responses }\end{array}$ & Percent $^{1}$ \\
\hline An independent consulting firm & 12 & 21 \\
Another Federal agency & 7 & 12 \\
Bureau of Reclamation & 4 & 7 \\
A stakeholder group & 2 & 4 \\
Academia & 2 & 4 \\
I don't know: & 2 & 4 \\
A State agency & 1 & 2 \\
\hline
\end{tabular}

\footnotetext{
${ }^{1}$ The percentage of respondents $(n=30)$ within each affiliation type.
} 
The majority of respondents rated the effect of the DRP on the 5-point "negative effect" $(-2)$ to "positive effect" (+2) scale as somewhat positive (fig. 4) with the median and mode values equal to 1. Only one respondent indicated that they did not know the effect of the DRP on the dispute over science.

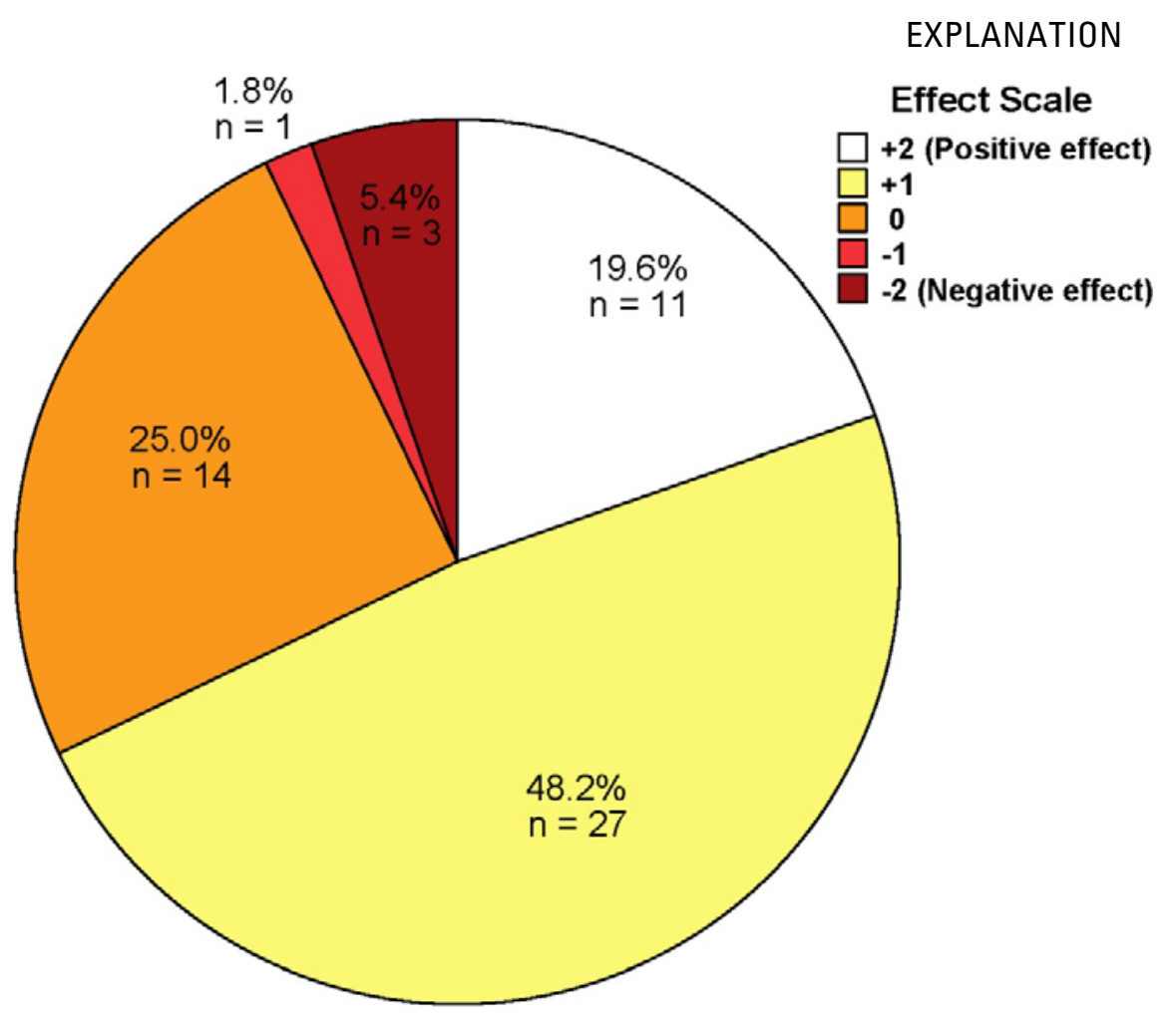

Figure 4. How respondents rated the perceived effects of dispute resolution professionals on dispute resolution processes on a 5-point "negative effect" to "positive effect" scale. The percentages within each category of the effect scale do not include the "I don't know" response $(n=56)$.

DRPs were utilized more frequently in conjunction with some dispute resolution method types than others (Pearson's $\chi^{2}(6, n=316)=17.28, p=0.008$, excluding "I don't know" responses). Post hoc $z$ tests revealed that DRPs were more likely to be involved in disputes where either of the method categories "public education, data sharing, and results dissemination" and "adaptive management" were also used than in conjunction with the other method types.

Respondents' rating of the effect of the DRP on the resolution process did not differ across the different dispute resolution method types used (Kruskall-Wallis $\chi^{2}(6, n=57)=4.00, p=0.677$ ).

\section{Outcomes of Disputes over Science}

\section{Objectives and Hypotheses}

The main objectives were to determine (1) the most common outcomes of disputes over science, (2) whether any of the dispute resolution method categories have different dispute outcomes than the others, (3) whether the use of any dispute resolution method result in different dispute outcomes from 
disputes for which no method was used, and (4) whether differences in respondents' experiences were associated with their professional background and experience.

For the first objective, we expected to find that most of the disputes over science would still be ongoing or unresolved because the literature suggests that competing and often incompatible interests frequently underlie disputes over science during decision-making processes for limited natural resources, and these kinds of disputes are very difficult to resolve (Ozawa and Susskind, 1985; Nie, 2003; Sabatier and others, 2005; Scholz and Stiftel, 2005). In addition, we asked respondents to think only of the most recent dispute over science in which they had been involved. Thus, more recent disputes are more likely to be ongoing than older disputes. We did not have any a priori predictions for the last three objectives.

\section{Summary of Findings}

- The majority of respondents described a dispute over science that was still ongoing. Twenty-eight percent selected that "the dispute was resolved," and even a smaller percentage selected "the dispute was not resolved and is not expected to be resolved."

- There was no association between the dispute resolution method type used and the outcomes of the disputes over science.

- The use of a dispute resolution method did not have different dispute outcomes from disputes where no method was used.

- In general, respondents that had worked at Reclamation for less than 5 years were more likely to indicate that disputes were ongoing and less likely to indicate that disputes were resolved, and those that had worked at Reclamation for greater than 20 years were less likely to indicate that disputes were ongoing and more likely to indicate that disputes were resolved.

\section{Detailed Results}

Responses on the status of the disputes over science are described in figure 5.

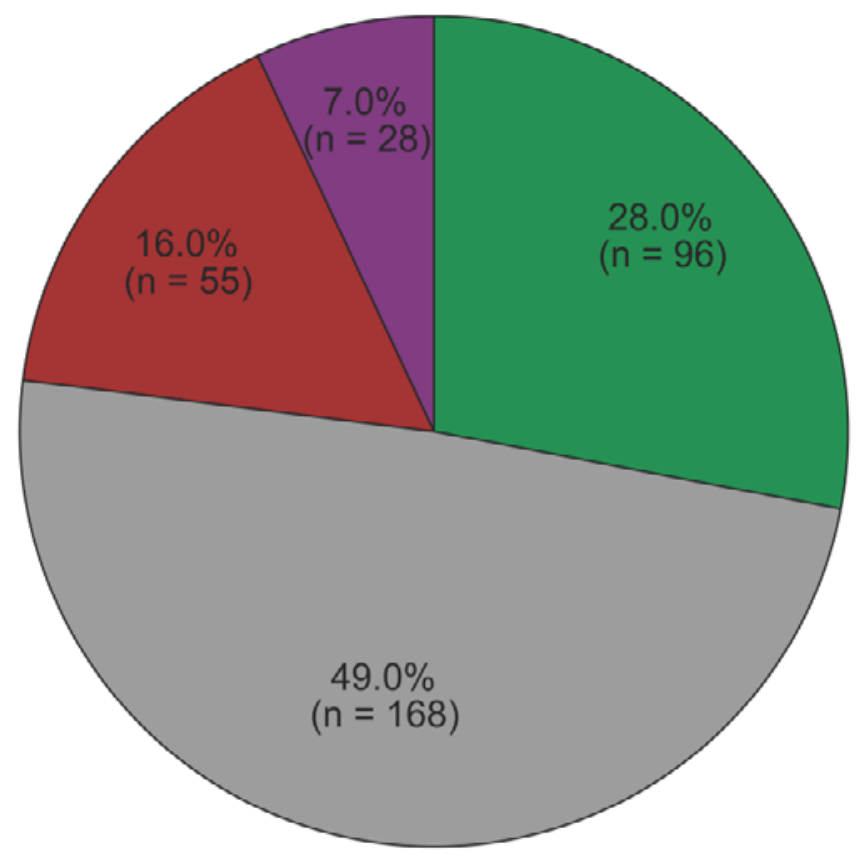

\section{EXPLANATION}

Outcomes of Disputes over Science

$\square$ The dispute was resolved

The dispute resolution process is ongoing

The dispute was not resolved and is not expected to be resolved

$\square$ I don't know

Figure 5. Proportions and sample sizes of responses in each of the dispute outcome categories. 
Proportions of responses within each of the dispute outcome categories (excluding "I don't know" responses) did not significantly differ across the dispute resolution method categories (Pearson's $\left.\chi^{2}(12, n=319)=13.31, p=0.347\right)$. Proportions of responses within each of the dispute outcome categories (excluding "I don't know" responses) did not significantly differ between those that used a dispute resolution method versus the disputes where no method was used (Pearson's $\chi^{2}(2, n=319)=$ $0.474, p=0.789)$.

A GZLM for the dispute outcomes revealed that the main effect of primary professional training was not significant (Wald $\left.\chi^{2}(4, n=283)=7.35, p=0.118\right)$, and the main effect of supervisory position was not significant $\left(\right.$ Wald $\left.\chi^{2}(1, n=283)=2.12, p=0.145\right)$. The reduced GZLM revealed that the main effect of number of years worked at Reclamation was significant (Wald $\chi^{2}(4, n=286)=17.17, p=$ $0.002)$.

Post hoc $z$ tests of the contingency table of decision outcomes by the number of years worked at Reclamation indicated that respondents that had worked for Reclamation for less than 5 years were more likely than other respondents to indicate that the dispute was still ongoing and less likely to indicate that the dispute was resolved (Pearson's $\chi^{2}(8, n=286)=20.72, p=0.008$ ). Furthermore, respondents that had worked for Reclamation for more than 20 years were less likely than other respondents to indicate that the dispute was still ongoing and more likely than expected to indicate that the dispute was resolved.

\section{Resolved Disputes over Science}

\section{Objectives and Hypotheses}

The main objective was to determine whether the disputes over science that were resolved were more frequently resolved within Reclamation or outside of Reclamation. If disputes were resolved within Reclamation, then we tried to determine at what level they were resolved, and if disputes were resolved outside of Reclamation, then we tried to determine which party was responsible for resolving the dispute. We did not have any a priori predictions regarding these objectives.

\section{Summary of Findings}

- Disputes were most frequently resolved within Reclamation at the level at which the disputes originated.

- When resolved outside of Reclamation, disputes over science were most frequently resolved by another Federal agency.

\section{Detailed Results}

If resolved, the majority of respondents described disputes that were resolved within Reclamation (57 percent $(n=48)$ ), rather than outside of Reclamation (33 percent $(n=28)$. Only 10 percent $(n=8)$ of respondents selected "I don't know." If disputes were resolved within Reclamation, the majority of respondents described disputes that were resolved at the level at which they originated (69 percent $(n=33))$. In 29 percent $(n=14)$ of responses, higher level officials in Reclamation had resolved the disputes over science, and 10 percent $(n=8)$ of responses indicated that they did not know where the disputes were resolved. If the disputes were resolved outside of Reclamation, respondents most frequently indicated that another Federal agency resolved the dispute $(43$ percent $(n=12))$, followed by the courts, academia, and State agencies (each with 11 percent $(n=2)$ ). Either two or only 
one respondent indicated that disputes were resolved by elected officials, a Consultant Review Board, or an international entity.

\section{Outcomes of Decisions Hindered by Disputes over Science}

\section{Objectives and Hypotheses}

The main objectives were to determine (1) the most common outcomes of the decisions that were hindered by the disputes over science, (2) whether any of the dispute resolution method categories have different decision outcomes than the others, (3) whether the use of any dispute resolution method result in different decision outcomes from disputes for which no method was used, and (4) whether differences in respondents' experiences were associated with their professional background and experience.

We expected to find that most of the decision processes that had been hindered by these disputes over science would still be ongoing or would have been called to a halt because the disputes over science would be sufficiently problematic if not resolved (Ozawa and Susskind, 1985; Nie, 2003; Sabatier and others, 2005; Scholz and Stiftel, 2005) that they would continue to hinder the decisionmaking processes. We also expected this because we asked respondents to respond to survey questions thinking of the most recent dispute over science that they had experienced and more recent disputes may not have had sufficient time to reach resolution.

The fifth and final objective was to learn whether the final outcomes of disputes over science potentially influenced the final outcomes of the decisions that were hindered by them. We predicted that disputes over science that were not resolved or ongoing would be associated with decision processes that were either not resolved or ongoing.

\section{Summary of Findings}

- As expected, the majority of respondents indicated that the decision process that had been hindered by the dispute over science was still ongoing. Roughly 1 out of every 3 respondents indicated that "the decision was made," and roughly 1 out of every 10 respondents indicated that "the decision has not been made and it is uncertain as to whether it will be made."

- There was no association between dispute resolution method type and the outcomes of the decisions that were hindered by the dispute over science.

- The use of a dispute resolution method also did not have different dispute outcomes from using no method.

- The reported outcomes of decisions that were hindered by the disputes over science were significantly associated with the number of years that respondents had worked at Reclamation. Respondents that had worked for Reclamation for more than 10 years were more likely than other respondents to indicate that the decision was made and those that had worked for Reclamation for fewer than 5 years were less likely. In addition, respondents that had worked for Reclamation for more than 10 years were less likely than other respondents to indicate that "the decision-making process is ongoing" and those that had worked for Reclamation for fewer than 5 years were more likely.

- The outcomes of the decisions that were hindered by the disputes over science were significantly associated with the outcomes of the disputes over science. As predicted, the likelihood that decisions were made was higher when the disputes over science had been resolved. When dispute resolution processes were ongoing, the decision-making processes were more likely to be ongoing as well. 
Also, when respondents selected "the dispute was not resolved and is not expected to be resolved," they were more likely to indicate that "the decision was not made and it is uncertain as to whether it will be made."

\section{Detailed Results}

Responses on the status of the decision that was hindered by the dispute over science are described in fig. 6 .

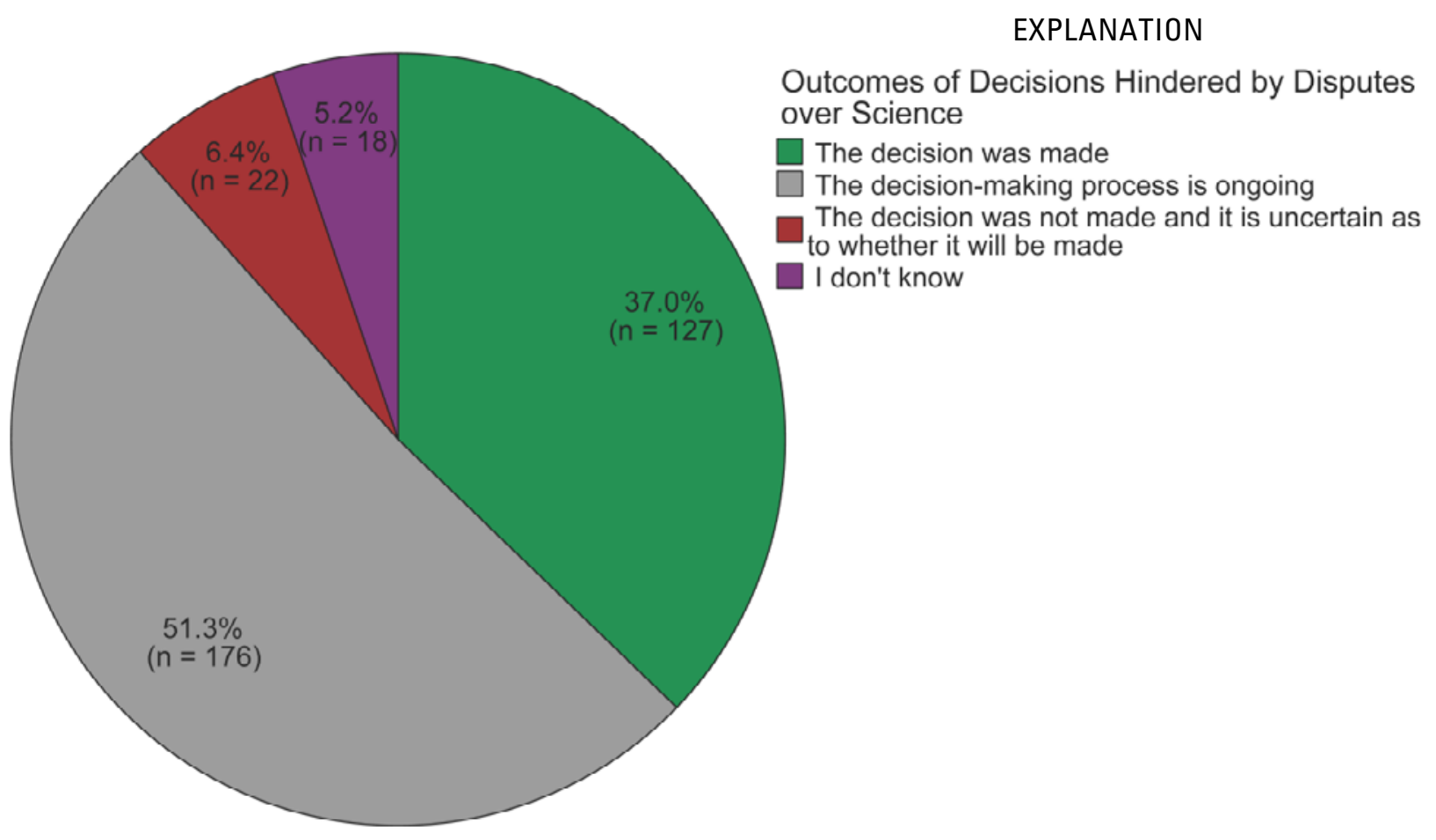

Figure 6. Proportions and sample sizes of responses in each of the decision outcome categories.

Proportions of responses within each of the decision outcome categories (excluding "I don't know" responses) did not significantly differ across the dispute resolution method categories (Pearson's $\left.\chi^{2}(12, n=325)=4.61, p=0.970\right)$. Proportions of responses within each of the decision outcome categories (excluding "I don't know" responses) did not significantly differ between those that used a dispute resolution method versus the disputes where no method was used (Pearson's $\chi^{2}(2, n=325)=$ $1.00, p=0.606)$.

A GZLM for the decision outcomes revealed that the main effect of primary professional training was not significant (Wald $\chi^{2}(4, n=289)=4.93, p=0.295$ ), and the main effect of supervisory position was not significant (Wald $\left.\chi^{2}(1, n=289)=0.028, p=0.868\right)$. A reduced GZLM revealed that the main effect of the number of years worked at Reclamation was significant (Wald $\chi^{2}(4, n=292)=$ $20.17, p<0.001)$.

Post hoc $z$ tests of the contingency table of decision outcomes by the number of years worked at Reclamation revealed that respondents that had worked for Reclamation for more than 10 years were more likely than expected to indicate that the decision was made and those that had worked for Reclamation for fewer than five years were less likely than expected (Pearson's $\chi^{2}(8, n=292)=25.04$, $p=0.002$ ). Furthermore, respondents that had worked for Reclamation for more than 10 years were less 
likely than expected to indicate that the decision-making process is ongoing and those that had worked for Reclamation for fewer than five years were more likely than expected.

Proportions of responses within each of the decision outcome categories were significantly

associated with proportions of responses within each of the dispute outcome categories (Pearson's $\chi^{2}(4$, $n=314)=166.46, p<0.001$; fig. 7).

\section{Outcomes of Decisions Hindered by Disputes over Science}
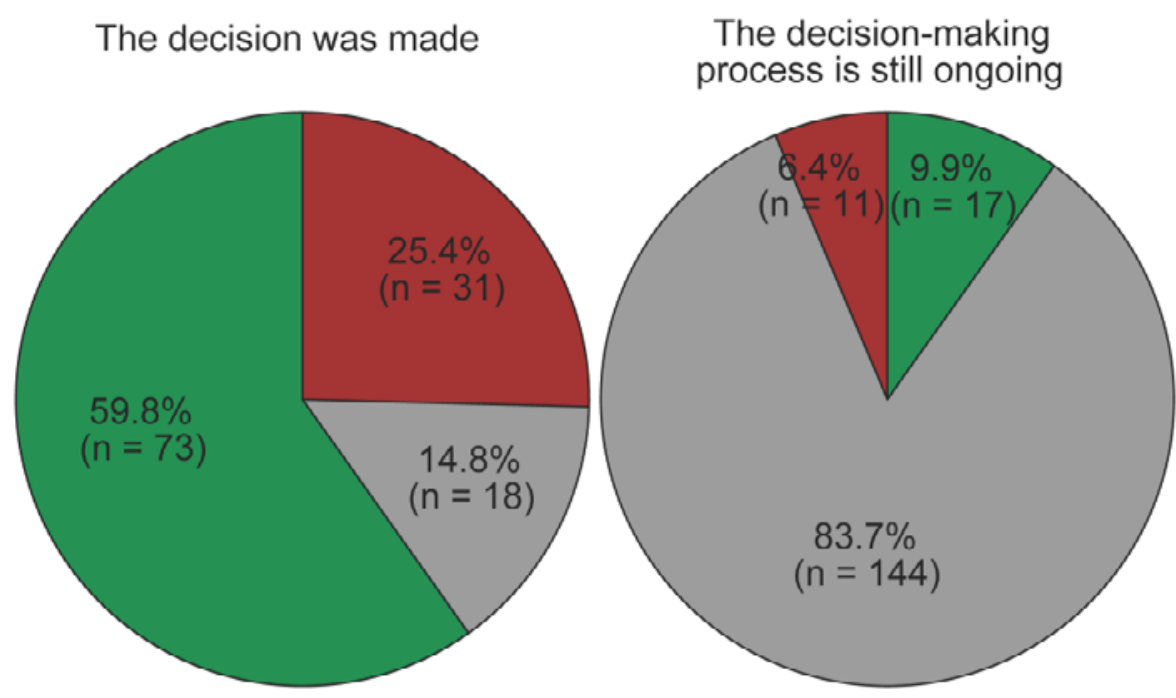

The decision was not made and it is uncertain as to whether it will be

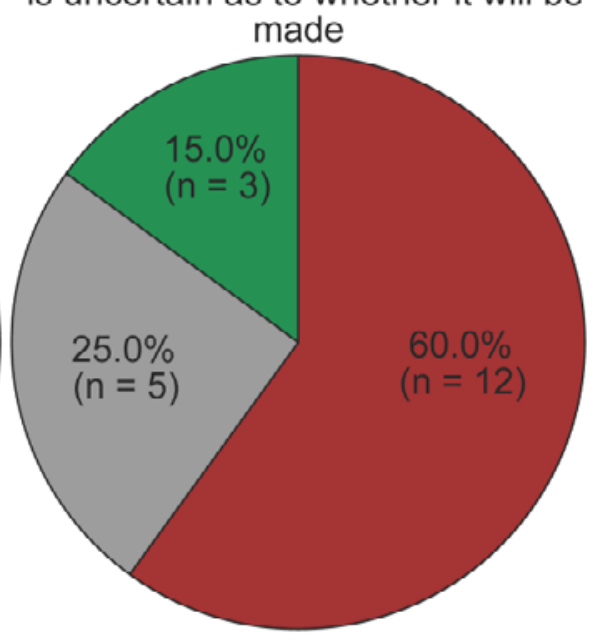

\section{EXPLANATION \\ Outcomes of Disputes Over Science}

The dispute was resolved

The dispute resolution process is ongoing

The dispute was not resolved and is not expected to be resolved

Figure 7. Proportions and sample sizes for each of the categories of dispute outcomes within each of the decision outcome categories (excluding "I don't know" responses).

\section{Experiences with Multiple Disputes over Science and (or) Dispute Resolution Method Types}

\section{Objectives and Hypotheses}

The main objectives were to determine (1) how commonly Reclamation employees in technical, scientific, and managerial positions have experience with the use of multiple dispute resolution method types and (2) whether differences in respondents' experiences were associated with their professional background and experience. We did not have any a priori predictions regarding these objectives.

\section{Summary of Findings}

- Half of the respondents indicated that they had experience with zero or only one dispute resolution method type. Of the remaining respondents, 22 percent had experience with three or more dispute resolution methods categories. 
- Respondents' primary professional training was significantly associated with their probability of having experience with multiple dispute resolution method types. Respondents trained in "engineering" were more likely than expected to indicate that they had experience with zero or only one dispute resolution method type, and respondents trained in "biological sciences" were more likely than expected to indicate that they had experience with at least three dispute resolution method categories.

\section{Detailed Results}

Out of the 347 respondents that completed loop 1 of the survey, 50 percent $(n=173)$ of respondents completed only loop 1, 28 percent $(n=97)$ completed two loops of the survey, and 22 percent $(n=77)$ completed all three loops of the survey.

A GZLM for the number of loops completed revealed that the main effect of supervisory position was not significant when taking into account primary professional training (Wald $\chi^{2}(1, n=305)$ $=0.223, p=0.636)$, and the main effect of years worked at Reclamation was not significant when taking into account primary professional training and supervisory position (Wald $\chi^{2}(4, n=305)=4.37, p=$ 0.359). A reduced GZLM revealed that the main effect of primary professional training was significant (Wald $\left.\chi^{2}(4, n=308)=18.34, p=0.001\right)$.

Respondents trained in "engineering" were more likely to complete just one loop than expected in post hoc tests, and respondents trained in "biological sciences" were less likely to fill out just one loop than expected and were more likely to fill out all three loops than expected in post hoc tests of the contingency table of survey loops completed by primary professional training (Pearson's $\chi^{2}(16, n=308)$ $=21.17, p=0.007)$.

\section{Evaluations of Dispute Resolution Resources for Reclamation Employees}

\section{Objectives and Hypotheses}

The primary objective was to determine which of the proposed resources would be the most useful for Reclamation employees that become involved in disputes over science. We did not have any $a$ priori predictions for this objective.

\section{Summary of Findings}

- Two of the potential dispute resolution resource options were considered to be more useful than the others.

- Respondents rated "a training class" and then "a bibliography of related literature" as the most useful of the five potential resources.

\section{Detailed Results}

A Friedman test revealed significant differences in how respondents rated the five potential resources for helping Reclamation employees resolve disputes over science (Friedman's $\chi^{2}(4, n=243)=$ 45.73, $p<0.001$ excluding responses that selected "I don't know" or "not applicable" for any of the five resources). Approximately 1 out of every 5 respondents rated "a training class" and then "a bibliography of related literature" as "very useful" (a scale value of 5), and approximately 1 out of 10 respondents rated these resources as "not useful" (a scale value of 1; table 8). In contrast, the resource "an Indefinite Delivery/Indefinite Quantity (IDIQ) Contract for conflict services" was rated as the least useful of the five potential resources. Approximately 1 out of 10 respondents rated this resource as "very useful," and 
1 out of 5 respondents rated this resource as "not useful." A small percentage of the respondents gave "not applicable" (range 1-2 percent of respondents) or "I don't know" answers (range 6-16 percent of respondents) for each of the factors.

The distribution of respondents' ratings did not significantly differ between the dispute resolution method categories for any of the potential dispute resolution resources.

Table 8. Sample sizes, medians, modes, proportions of responses within each category of the 5-point "not useful" to "very useful" scale, and Friedman's mean rank values for each of the different potential resources intended to help Reclamation employees resolve disputes over science.

\begin{tabular}{|c|c|c|c|c|c|c|c|c|c|}
\hline \multirow{2}{*}{$\begin{array}{l}\text { Potential resources to help } \\
\text { Reclamation employees resolve } \\
\text { disputes over science }\end{array}$} & \multirow{2}{*}{$\begin{array}{l}\text { Number of } \\
\text { responses }^{1}\end{array}$} & \multirow{2}{*}{ Median } & \multirow[t]{2}{*}{ Mode } & \multicolumn{5}{|c|}{$\begin{array}{c}\text { Scale } \\
\text { Not useful to very useful }\end{array}$} & \multirow{2}{*}{$\begin{array}{l}\text { Freidman's } \\
\text { mean rank }\end{array}$} \\
\hline & & & & 1 & 2 & 3 & 4 & 5 & \\
\hline $\begin{array}{l}\text { (1) Bibliography of related } \\
\text { literature }\end{array}$ & 290 & 4 & 4 & $10 \%$ & $16 \%$ & $23 \%$ & $28 \%$ & $22 \%$ & 3.22 \\
\hline (2) Training class & 289 & 4 & 4 & $9 \%$ & $15 \%$ & $25 \%$ & $29 \%$ & $22 \%$ & 3.34 \\
\hline $\begin{array}{l}\text { (3) Reclamation manual on } \\
\text { managing disputes over science }\end{array}$ & 284 & 3 & 3 & $15 \%$ & $19 \%$ & $29 \%$ & $24 \%$ & $13 \%$ & 2.88 \\
\hline $\begin{array}{l}\text { (4) Web site or SharePoint site } \\
\text { devoted to managing disputes } \\
\text { over science }\end{array}$ & 278 & 3 & 4 & $14 \%$ & $18 \%$ & $27 \%$ & $29 \%$ & $13 \%$ & 2.98 \\
\hline $\begin{array}{l}\text { (5) Indefinite } \\
\text { Delivery/Indefinite Quantity } \\
\text { (IDIQ) Contract for conflict } \\
\text { services }\end{array}$ & 255 & 3 & 3 & $20 \%$ & $21 \%$ & $30 \%$ & $17 \%$ & $13 \%$ & 2.58 \\
\hline
\end{tabular}

${ }^{1}$ The number of responses for each resource and the calculated medians, modes, and percentages within each category in the 5-point not contested to highly contested scale do not include the "not applicable" and "I don't know" responses for that resource.

${ }^{2}$ Calculated from the responses $(n=243)$ that did not select "I don't know" or "not applicable" for any of the five resources.

\section{Acknowledgments}

We would like to thank Curtis A. Brown and Douglas R. Clark (U.S. Bureau of Reclamation) for their assistance with this project, Anthony Everette and Holly Miller (USGS Fort Collins Science Center) for their technological assistance with the Web survey, and Shannon Conk for testing the survey instrument. We also thank the individuals who completed the survey. This research was supported by funding from the Bureau of Reclamation, Agreement No. R11PG80819.

\section{References Cited}

AAPOR (American Association for Public Opinion Research), 2009, Standard definitions_Final dispositions of case codes and outcome rates for surveys (6th ed.): Ann Arbor, Mich., AAPOR, accessed December 27, 2010, at http://www.aapor.org/Standard_Definitions/2852.htm).

AAPOR (American Association for Public Opinion Research), 2010, Response rate calculator, v. 3.1 : Ann Arbor, Mich., AAPOR, accessed December 27, 2010, at http://www.aapor.org/Standard_Definitions/2852.htm). 
Abrams, N.E., and Berry, R.S., 1977, Mediation-A better alternative to science courts: Bulletin of the Atomic Scientists, April, p. 50-53.

Adler, P.S., Barrett, R.C., Bean, M.C., Birkhoff, J.E., Ozawa, C.P., and Rudin, E.B., 2001, Managing scientific and technical information in environmental cases-Principles and practices for mediators and facilitators: Tucson, Ariz., U.S. Institute for Environmental Conflict Resolution, and Western Justice Center Foundation, 76 p., available at http://www.mediate.com/articles/envir_wjc11.pdf.

Anderson, J.F., and Bingham, L., 1997, Upstream effects from mediation of workplace disputes: Some preliminary evidence from the USPS: Labor Law Journal, v. 48, p. 601-615.

Baruch, Y., and Holtom, B.C., 2008, Survey response rate levels and trends in organizational research: Human Relations, v. 61, no. 8, p. 1139-1160.

Becher, T., 1994, The significance of disciplinary differences: Studies in Higher Education, v. 19, no. 2, p. 151-161.

Bowersox, J., 2000, From water development to water management-Federal agency opportunism in an era of policy devolution: American Behavioral Scientist, v. 44, no. 4, p. 599-613.

Burkardt, N., Lamb, B.L., Taylor, J.G., and Waddle, T.J., 1995, Technical clarity in inter-agency negotiations-Lessons from four hydropower projects: Water Resources Bulletin, v. 31, no. 2, p. 187-198.

Coglianese, C., 1999, The limits of consensus: Environment, v. 41, no. 3, p. 28-33.

Dillman, D.A., Smyth, J.D., and Christian, L.M., 2009, Internet, mail, and mixed-mode surveys: The tailored design method: Hoboken, N.J., Wiley, 499 p.

Downey, R.G., and King, C.V., 1998, Missing data in Likert ratings-A comparison of replacement methods: The Journal of General Psychology, v. 125, no. 2, p. 175-191.

Ehrmann, J.R., and Stinson, B.L., 1999, Joint fact-finding and the use of technical experts, in Susskind, L., McKearnan, S., and Thomas-Larmer, J., eds., The consensus building handbook: A comprehensive guide to reaching agreement: Thousand Oaks, Calif., Sage Publications, p. 375-399.

Endangered Species Act (ESA), 1973,16 U.S.C. § 1531 et seq.

Hanemann, M., and Dyckman, C., 2009, The San Francisco Bay-Delta-A failure of decision-making capacity: Environmental Science \& Policy, v. 12, p. 710-725.

Henry, C.J., and Conrad, J.W., Jr., 2008, Scientific and legal perspectives on science generated for regulatory activities: Environmental Health Perspectives, v. 116, no. 1, p. 136-141.

Ison, R., Röling, N., and Watson, D., 2007, Challenges to science and society in the sustainable management and use of water-Investigating the role of social learning: Environmental Science \& Policy, v. 10, p. 499-511.

Johnson, B.L., 1999, The role of adaptive management as an operational approach for resource management agencies: Conservation Ecology, v. 3, no. 2, p. 8., available at http://www.consecol.org/vol3/iss2/art8/.

Koehler, B., and Koontz, T.M., 2008, Citizen participation in collaborative watershed partnerships: Environmental Management, v. 41, p. 143-154.

Koontz, T.M., and Thomas, C.W., 2006, What do we know and need to know about the environmental outcomes of collaborative management: Public Administration Review, v. 66, p. 111-121.

Koontz, T.M., Steelman, T.A., Carmin, J., Korfmacher, K.S., Moseley, C., and Thomas, C.W., 2004, Collaborative environmental management_-What roles for government?: Washington, D.C., Resources for the Future Press, 200 p.

Langfeldt, L., 2006, The policy challenges of peer review-Managing bias, conflict of interests and interdisciplinary assessments: Research Evaluation, v. 15, no. 1, p. 31-41. 
Lorie, M.A., and Cardwell, H.E., 2006, Collaborative modeling for water management: Southwest Hydrology, v. 5, no. 4, p. 26-27.

Mazur, A., 1973, Disputes between experts: Minerva, v. 11, p. 243-262.

NRC (National Research Council), 2004, Confronting the nation's water problems-The role of research: Washington, D.C., The National Academy Press, 310 p.

National Environmental Policy Act (NEPA), 1969,42 U.S.C. $§ 4321$ et seq.

Nie, M., 2003, Drivers of natural resource-based political conflict: Policy Sciences, v. 36, p. 307-341.

Ozawa, C.P., 1996, Science in environmental conflicts: Sociological Perspectives, v. 39, no. 2, p. 219-230.

Ozawa, C.P., 2005, Putting science in its place, in Scholz, J.T., and Stiftel, B., eds., Adaptive governance and water conflict—New institutions for collaborative planning: Washington, D.C., Resources for the Future Press, p. 185-195.

Ozawa, C.P., and Susskind, L., 1985, Mediating science-intensive policy disputes: Journal of Policy Analysis and Management, v. 5, no. 1, p. 23-39.

Pisani, D.J., 2003, Federal reclamation and the American West in the Twentieth century: Agricultural History, v. 77, no. 3, p. 391-419.

Quirk, P.J., 2005, Restructuring State institutions - The limits of adaptive leadership, in Scholz, J.T., and Stiftel, B., eds., Adaptive governance and water conflict- $-\mathrm{New}$ institutions for collaborative planning: Washington, D.C., Resources for the Future Press, p. 204-212.

Roberts, M.J., Thomas, S.R., and Dowling, M.J., 1984, Mapping scientific disputes that affect public policymaking: Science, Technology, and Human Values, v. 9, no. 1, p. 112-122.

Roeder, E., 2005, Aquifer storage and recovery-Technology and public learning, in Scholz, J.T., and Stiftel, B., eds., Adaptive governance and water conflict-New institutions for collaborative planning: Washington, D.C., Resources for the Future Press, p. 106-118.

Ruckelshaus, M.H., Levin, P., Johnson, J.B., and Kareiva, P.M., 2002, The Pacific salmon wars-What science brings to the challenge of recovering species: Annual Review of Ecological Systems, v. 33, p. 665-706.

Ruell, E., Burkardt, N., and Clark, D.R., 2010, Resolving disputes over science in natural resource agency decision making: U.S. Bureau of Reclamation, Technical Services Center Technical Memorandum 86-68211-10-01, 58 p.

Sabatier, P.A., Focht, W., Lubell, M., Trachtenberg, Z., Vedlitz, A., and Matlock, M., 2005, Collaborative approaches to watershed management, in Sabatier, P.A., Focht, W., Lubell, M., Trachtenberg, Z., Vedlitz, A., and Matlock, M., eds., Swimming upstream-Collaborative approaches to watershed management: Boston, Mass., MIT Press, p. 3-22.

Schmidtz, D., 2000, Natural enemies-An anatomy of environmental conflict: Environmental Ethics, v. 22, p. 397-408.

Scholz, J.T., and Stiftel, B., 2005, The challenges of adaptive governance, in Scholz, J.T., and Stiftel, B., eds., Adaptive governance and water conflict-New institutions for collaborative planning: Washington, D.C., Resources for the Future Press, p. 1-11.

Shih, T., and Fan, X., 2008, Comparing response rates from web and mail surveys-A meta-analysis: Field Methods, v. 20, no. 3, p. 249-271.

Shinn, G., Baker, M., and Briers, G., 2007, Response patterns-Effect of day of receipt of an e-mailed survey instrument on response rate, response time, and response quality: Journal of Extension, v. 45, no. 2, article number 2RIB4. 
Stiftel, B., and Scholz, J.T., 2005, Conclusions-The future of adaptive governance, in Scholz, J.T., and Stiftel, B., eds., Adaptive governance and water conflict-New institutions for collaborative planning: Washington, D.C., Resources for the Future Press, p. 224-238.

Ury, W.L., Brett, J.M., and Goldberg, S.B., 1988, Getting disputes resolved-Designing systems to cut the costs of conflict: San Francisco, Calif., Jossey-Bass Inc., Publishers, 201 p.

van de Wetering, S.B., and McKinney, M., 2006, The role of mandatory dispute resolution in Federal environmental law-Lessons from the Clean Air Act: Journal of Environmental Law and Litigation, v. 21, p. 1-46.

von Meier, A., 1999, Occupational cultures as a challenge to technological innovation: IEEE

Transactions on Engineering Management, v. 46, no. 1, p. 101-114.

Wagenet, L.P., and Pfeffer, M.J., 2007, Organizing citizen engagement for democratic environmental planning: Society and Natural Resources, v. 20, p. 801-813.

Yun, G.W., and Trumbo, C.W., 2000, Comparative response to a survey executed by post, e-mail, and Web form: Journal of Computer-Mediated Communication, v. 6, no. 1, p. 0. doi: 10.1111/j.10836101.2000.tb00112.x. 
Appendixes 


\section{Appendix 1}

\section{Web Survey Questions}

Unit 1

\section{Question 1}

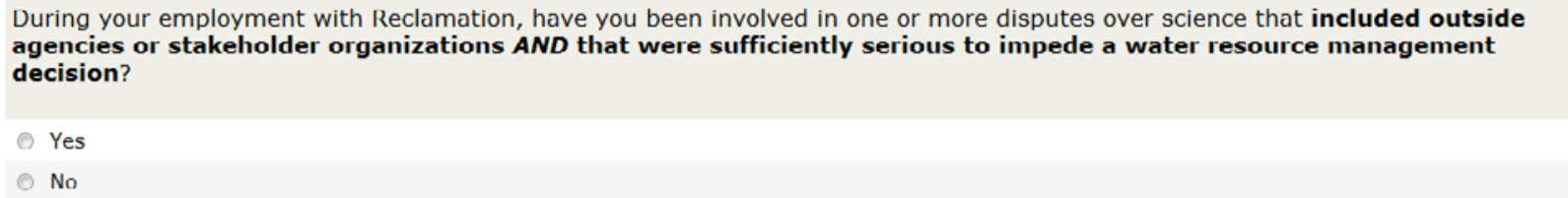

\section{Branch 1a}

If respondents selected "no" in question 1, they were sent to the final unit 10 of the survey (professional background questions) before they submitted their surveys.

\section{Branch $1 b$}

If respondents selected "yes" in question 1, they were sent to question 2.

\section{Question 2}

\section{In these disputes over science, have you been involved in the use of any of the following methods to help resolve the} conflict?

Direct Discussions Between or Among Scientists:

Processes that bring technical experts involved in a science dispute together to identify areas of agreement and disagreement, data needs and gaps, scientific protocols, and potential approaches to resolving technical disputes.

\section{Independent Expert Review:}

One or more outside experts review the disputed science and reach conclusions regarding the weight of the evidence and the adequacy of the science.

Reclamation Undertakes More Science and Analysis Independently of the Other Parties:

Reclamation undertakes additional studies or analyses in an effort to address concerns or conflicts.

\section{Active Collaboration in Research and Analysis:}

The outside partles Involved In the dispute engage with Reclamation In collaborative science, jolntly undertaking sclentific training, hypothesis development, data collection, model building, or data analysis.

Public Education, Data Sharing, and Results Dissemination:

Outreach activities designed to Inform the public and stakeholders about the technical Issues, existing data and science, and Reclamation's analysis of the information.

\section{Adaptive Management:}

A planned program of experimentation and adaptive decision-making based on scientific feedback used to address uncertainties or differences over science, and the management of water and related resources.

\section{Other (you will be asked to briefly describe how this method differs from those listed above).}

(1) Yes, I have been involved in the use of one or more of these methods.

No, I have not been involved in the use of any of these methods. 


\section{Branch 2a}

If respondents selected "no" or "I don't know" in question 2, they were sent on to unit 3.

\section{Branch $2 b$}

If they selected "yes" in question 2, they were sent on to unit 2.

Unit 2 (Beginning of Loop 1)

\section{Question 1}

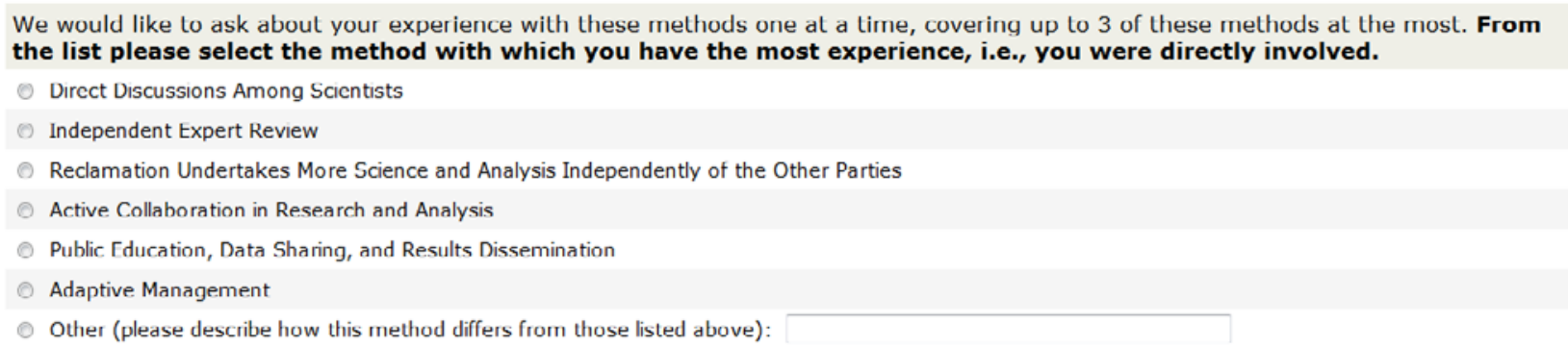

Unit 3 (Beginning of Loops 2 and 3)

\section{Comment 1}

Having identified the method with which you have the most experience, now focus on the most recent dispute over science in which that method was used. Briefly list the scientific issues that were under dispute below:

\section{Question 1}

Please indicate the extent to which the following factors were contested In thls most RECENT dIspute over sclence:
Highly
Contested
Whether or not the existing science addressed
the critical issues:
The quality of the data used:
The inference(s) drawn from the science:
The level of uncertainty in the science:
The need for additional scientific investigation:
Whether or not science should be the basis for
the management decision:
The qualifications of the scientists who
produced the science:


Comment 2

If other factors were contested in this most recent dispute over science, please list them here:

\section{Question 2}

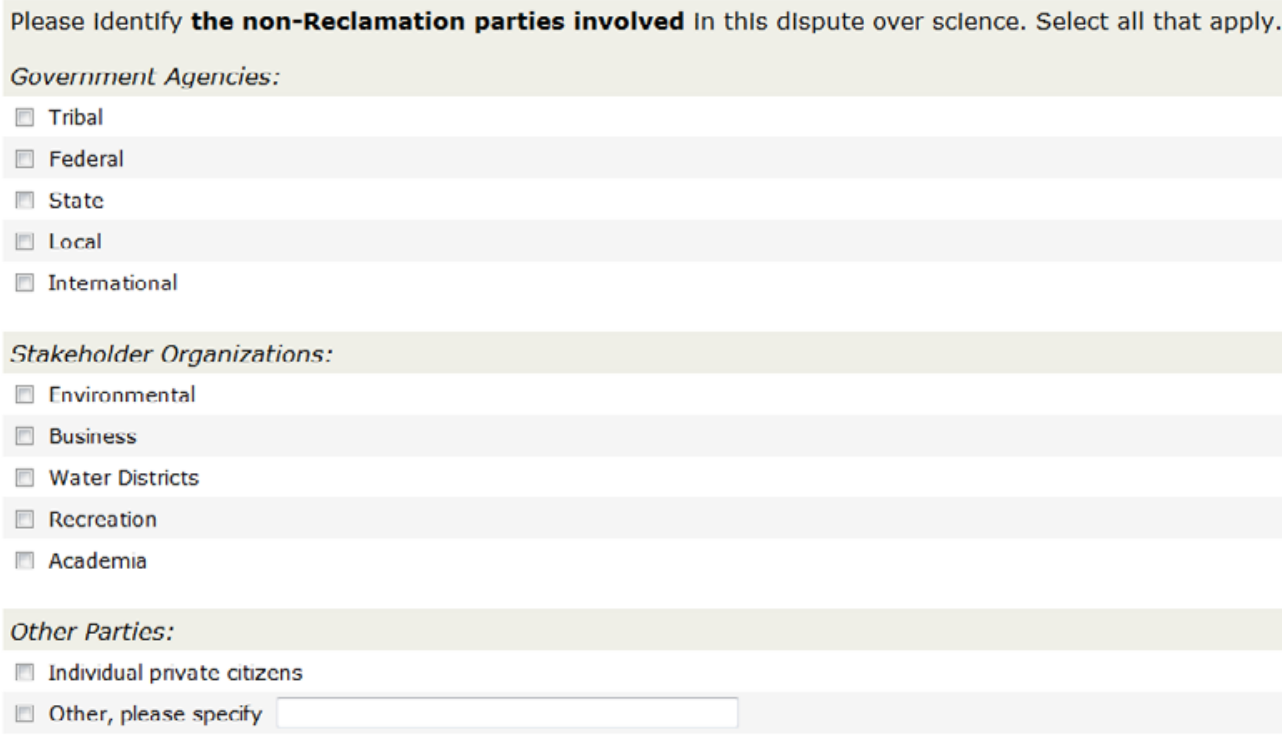

\section{Branch 1a}

Respondents who had answered "yes" to question 2 in unit 1 were now sent on to unit 4 .

Branch 1b

Respondents who answered "no" or "I don't know" to question 2 in unit 1 were now sent on to unit 5. 
Unit 4

\section{Question 1}

\begin{tabular}{|c|c|c|c|c|c|c|c|}
\hline & $\begin{array}{l}\text { Strongly } \\
\text { Disagree } \\
-2\end{array}$ & -1 & 0 & +1 & $\begin{array}{l}\text { Strongly } \\
\text { Agree } \\
+2\end{array}$ & Not Applicable & $\begin{array}{l}\text { 1 Don't } \\
\text { Know }\end{array}$ \\
\hline $\begin{array}{l}\text { This method fostered communication about } \\
\text { the scientific issues. }\end{array}$ & $\theta$ & $\theta$ & 0 & $\theta$ & 0 & 0 & $\Theta$ \\
\hline $\begin{array}{l}\text { This method resolved differences over } \\
\text { interpretation of the scientific results. }\end{array}$ & 0 & $\Theta$ & 0 & $\theta$ & 0 & $\odot$ & 0 \\
\hline $\begin{array}{l}\text { This method created incentives to reach } \\
\text { agreement on the dispute over science. }\end{array}$ & $\Theta$ & $\theta$ & $\theta$ & 0 & 0 & $\odot$ & $\theta$ \\
\hline $\begin{array}{l}\text { This method increased the scientific credibility } \\
\text { of Reclamation's position. }\end{array}$ & $\odot$ & $\theta$ & 0 & $\theta$ & 0 & $\odot$ & 0 \\
\hline $\begin{array}{l}\text { The time required for this method was } \\
\text { reasonable for Reclamation. }\end{array}$ & 0 & 0 & 0 & 0 & 0 & 0 & 0 \\
\hline $\begin{array}{l}\text { The monetary cost required for this method } \\
\text { was reasonable for Reclamation. }\end{array}$ & 0 & 0 & 0 & 0 & 0 & 0 & 0 \\
\hline $\begin{array}{l}\text { This method made it possible to move forward } \\
\text { in the absence of agreement over science. }\end{array}$ & 0 & 0 & 0 & 0 & 0 & 0 & 0 \\
\hline $\begin{array}{l}\text { This method helped the process proceed to } \\
\text { the decision that was delayed by the dispute } \\
\text { over science. }\end{array}$ & 0 & 0 & 0 & 0 & 0 & 0 & 0 \\
\hline
\end{tabular}

\section{Comment 1}

Other comments about the effectiveness of this method:

Unit 5

\section{Question 1}

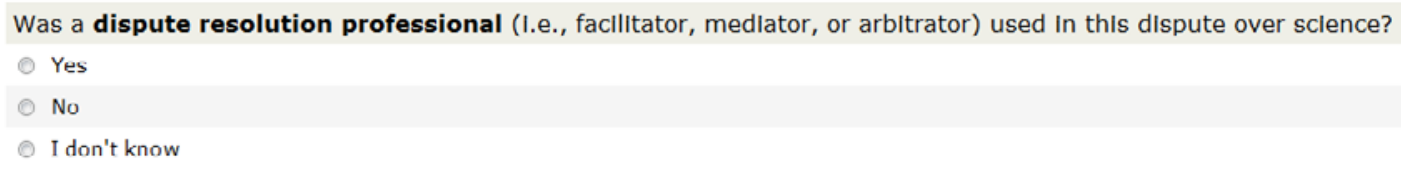

\section{Branch 1a}

Respondents that answered "yes" to question 1 were sent to question 2. 
Respondents that selected "no" or "I don't know" were sent on to unit 6.

\section{Question 2}

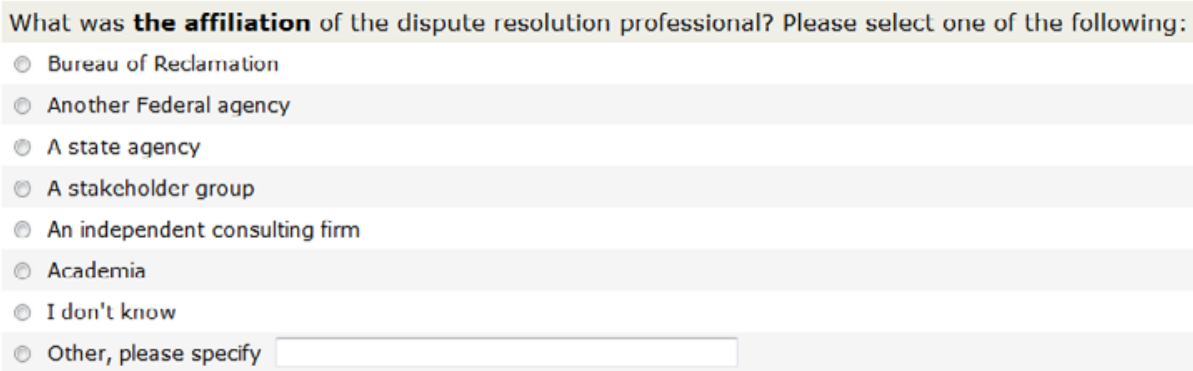

\section{Question 3}

Please Indicate the effect of using a dispute resolution professlonal In this process.
$\begin{aligned} & \text { Negative } \\ & \text { The effect } \\ & \text { professional: }\end{aligned}$

Unit 6

\section{Question 1}

What was the final outcome of this dispute over science?

The dispute was resolved.

C The dispute was not resolved and is not expected to be resolved.

- The dispute resolution process is ongoing.

( I don't know.

Other, please specify.

Branch 1a

If respondents selected "the dispute was resolved" in question 1, they were sent to question 2.

\section{Branch 1b}

If respondents selected any response option other than "the dispute was resolved" in question 1, they were sent on to unit 7. 


\section{Question 2}

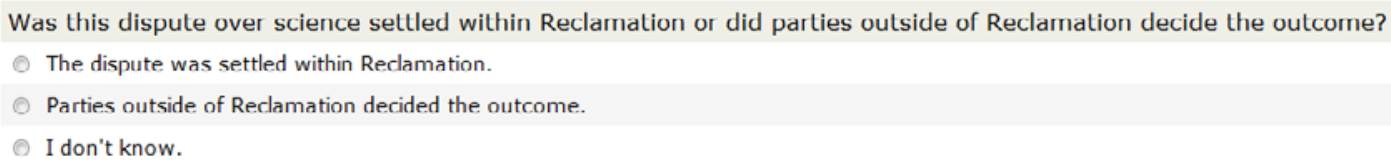

\section{Branch 2a}

If respondents selected "the dispute was settled within Reclamation" in question 2, they were sent to question 3.

Branch 2b

If respondents selected "parties outside of Reclamation decided the outcome" in question 2, then they were sent to question 4 .

\section{Branch 2c}

If respondents selected "I don't know," they were sent to unit 7.

\section{Question 3}

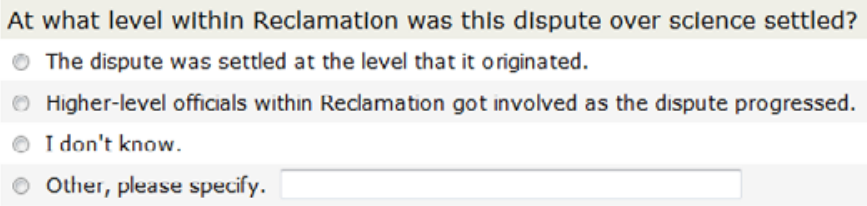

\section{Question 4}

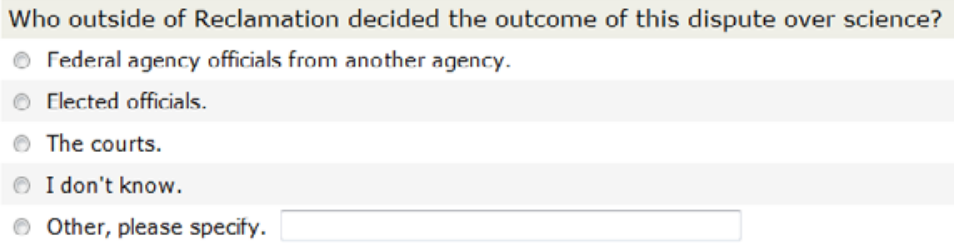


Unit 7

\section{Question 1}

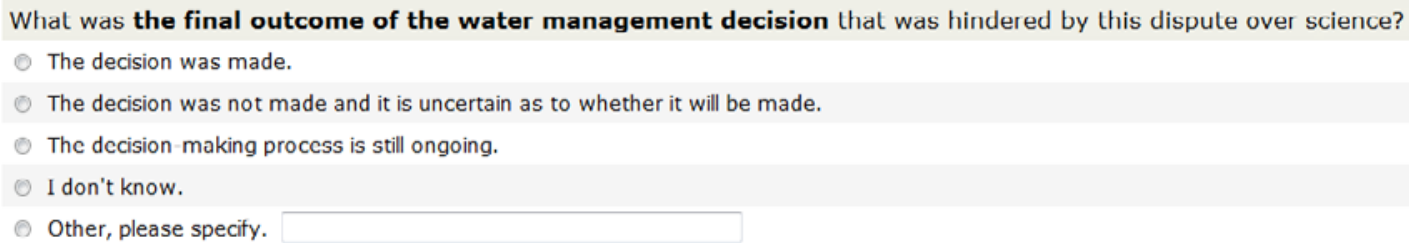

Comment 1 We recognize that these disputes over science are complex and that there is probably more to this dispute than we were able to ask in
the prevlous questlons. If there is anything about THIS DISPUTE over science that you would like to add, please do so in the box below:

\section{Branch 1a}

If respondents had answered in unit 1 that "no, I have not been involved in the use of any of these methods," they were now sent on to unit 9.

\section{Branch 1b}

If respondents had previously selected and described one of the categories of methods in unit 1 and they had only completed one or two loops of the survey thus far, they were sent to unit 8 .

\section{Branch 1c}

If respondents had already completed three loops of the survey, they were sent on to unit 9.

Unit 8

\section{Question 1}

Respondents were asked to select the dispute resolution method category with which they had the most experience from the list of remaining categories defined in unit 1 (this question was almost identical to 
question 1 in unit 2, except it excluded the method type(s) that were selected in previous loops and now included the response option "none of the above").

Branch 1a

If respondents to question 2 selected one of the remaining method categories, they were sent back to unit 3 (beginning of loop 2 and loop 3).

Branch 1b

If respondents to question 2 answered "none of the above," they were sent to unit 9.

Unit 9

Comment 1

Please comment here If there Is anything you would like to add about disputes over sclence In general:

\section{Question 1}

Please rate how useful the following resources would be for managing disputes over sclence:

A training class

A Reclamation manual on managing disputes over science

A website or SharePoint site devoted to managing disputes over science

An Indefinite Delivery/Indefinite Quantity (IDIQ) Contract for conflict services

$\begin{array}{cccc}\begin{array}{c}\text { Not Useful } \\ \mathbf{1}\end{array} & \boldsymbol{2} & \mathbf{3} & \mathbf{4} \\ 0 & 0 & 0 & 0 \\ 0 & 0 & 0 & 0 \\ 0 & 0 & 0 & 0 \\ 0 & 0 & 0 & 0 \\ 0 & 0 & 0 & 0\end{array}$

\begin{tabular}{|c|c|c|}
\hline $\begin{array}{c}\text { Very } \\
\text { Useful } \\
5\end{array}$ & Not Applicable & $\begin{array}{l}\text { I Don't } \\
\text { Know }\end{array}$ \\
\hline O & $\odot$ & 0 \\
\hline 0 & 0 & 0 \\
\hline 0 & 0 & 0 \\
\hline 0 & 0 & 0 \\
\hline 0 & 0 & 0 \\
\hline
\end{tabular}

\section{Comment 2}

What additional actions could Reclamation take to help you manage disputes over science? 
Unit 10

\section{Question 1}

Which area best describes your primary professional training?
Engineering
Biological Sciences
Physical Sciences
Social Sciences
Administration
Busincss
Law
Other, please specify

\section{Question 2}

Are you in a supervisory position?
Yes
No

\section{Question 3}

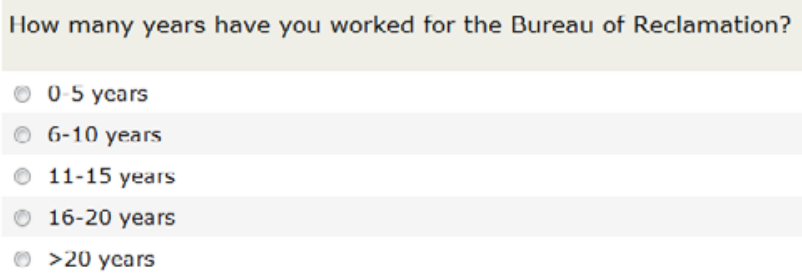

Respondents were then directed to submit their survey. 


\section{Appendix 2}

\section{Analyses of Survey Responses}

The minimum response rate, which is labeled Response Rate 1 in Standard Definitions: Final Dispositions of Case Codes and Outcomes Rates for Surveys, 6th Edition (AAPOR, 2009), was calculated using the Response Rate Calculator V3.1 (AAPOR, 2010). The minimum response rate is a conservative estimate that is comparable across survey methods (Shih and Fan, 2008). All subsequent analyses were completed using IBM ${ }^{\circledR}$ SPSS ${ }^{\circledR}$ Statistics Desktop V20.0.0 (IBM Corporation, Armonk, New York, U.S.A.).

\section{Respondents' Professional Background and Experience}

We jointly coded all of the "other, please specify" responses to the question about respondents' primary professional training and either put them into the categories that were provided or into one of the following additional categories: "technical trades and visitor services," "architecture," "computer science," and "law enforcement." We also combined the categories of "administration" and "business" and those that had indicated that their training was in realty or contracts into one category. We calculated frequencies of responses for each category of primary professional training, supervisory position, and the number of years employees had worked at Reclamation.

Type I analyses were used for all GZLM analyses because the model predictors would most likely have sequential effects, and we could only really interpret their main effects because two of the variables had five or more categories. Primary professional training would almost always have come before supervisory position was determined, and both of these would have occurred (or have not occurred) before the survey when respondents' tallied the total number of years they had worked at Reclamation thus far.

We used a GZLM with a multinomial distribution and a cumulative complementary log-log link function to evaluate the main effects of primary professional training (engineering, biological sciences, physical sciences, social sciences, administration/business/contracts/realty, law, technical trades/visitor services, architecture, computer science, law enforcement, other) and supervisory position (no, yes) on the number of years respondents' had worked at Reclamation (0-5 years, 6-10 years, 11-15 years, 1620 years, $>20$ years).

\section{Involvement in Disputes over Science}

We used a GZLM with a binomial distribution and logit link function to evaluate the main effects of primary professional training (engineering, biological sciences, physical sciences, social sciences, administration/business/contracts/realty, law, technical trades/visitor services, architecture, computer science, law enforcement, other), supervisory position (No, Yes), and the number of years worked at Reclamation ( $0-5$ years, $6-10$ years, $11-15$ years, $16-20$ years, $>20$ years) on respondents' probability of having been involved in a dispute over science (No, Yes).

We identified which primary professional training categories were more or less likely than the others to have been involved in a dispute over science using Pearson's Chi-square test to compare the probability of being involved in a dispute versus the different primary professional training categories and using post hoc $z$ tests ( $\alpha=0.05$ using a Bonferroni correction for multiple tests). 


\section{Dispute Characteristics}

We only included survey responses to questions in loop 1 of the survey in subsequent analyses on question units 1-7 and excluded information obtained in loops 2 and 3 because it became apparent from the open-ended comments that neither the disputes over science nor the methods used in the dispute were independent across survey loops. Furthermore, because some of the respondents could have described the same dispute over science in loop 1 of their surveys (thus, disputes and dispute resolution attempts were not independent across respondents), all of the following results represent frequencies of respondents' experiences rather than the actual frequencies of disputes and dispute resolution attempts. Also, we only included the incomplete surveys of respondents that had been involved in a dispute over science and had also answered the survey questions about the characteristics of the dispute and the performance questions (survey question units 1-7) in further analyses with the completed surveys.

We jointly coded all of the open-ended comments that described the scientific issues behind the disputes over science into general categories of issues. More than one issue category per dispute was possible. We only coded a dispute as involving a Federally listed species if the respondent clearly identified it as such. Comments that mentioned that plant or animal species or species' requirements were involved but did not give the species name or the Federal protection status of the species were coded simply as "native species" (unless they were identified as a non-native or invasive species), because we did not have enough information to identify whether or not a Federally listed species under the ESA (1973) was involved. We preferred to underestimate rather than overestimate the frequency of responses that involved Federally listed species.

We calculated the number of different issue types involved per response and calculated the range and proportion of responses that included one, two, three, or four issue types. We then calculated the proportions of responses for each of the underlying issue types (respondents could select all that apply).

We calculated the number of different party types involved per response and calculated the mean, standard deviation, and range for the number of party types across respondents. We then calculated the proportions of responses for each of the outside party types that were involved (respondents could select all that apply).

\section{Dispute Resolution Methods}

We calculated the proportions of responses that selected each of the dispute resolution method categories (respondents could only select one).

\section{Number of Issue and Party Types Involved in Dispute Versus Method Types Used}

We compared the probability that one, two, three, or four different issue types were involved for each dispute resolution method category (including disputes for which no method was used) using Pearson's Chi-square tests.

We compared the mean number of outside party types involved per response between the dispute resolution method categories (including disputes for which no method was used) using a one-way ANOVA. We also compared the mean number of party types involved for responses where no dispute resolution process was used versus those where a dispute resolution process had been used using an independent-samples $t$ test. 


\section{Contested Factors in Disputes over Science}

We calculated the median, mode, and proportions for each category in the ordered-category scale, which described how contested each factor was in the dispute. We assessed which of the seven potentially contested factors was rated as being the most or least contested using a Friedman test and by comparing the median and mode for each factor. We compared how respondents rated the degree to which each of the seven potentially disputed factors were contested between the dispute resolution method categories (including disputes for which no method was used) using Kruskal-Wallis one-way ANOVAs. These seven ordered-category items were not summed and analyzed using parametric statistics, because the items did not clearly form a meaningful construct when combined.

\section{Evaluations of Performance of Dispute Resolution Method Types}

For each method type, we assessed whether respondents rated any of the eight performance statements (unit 4, question 1) differently from the others and calculated the relative rank of statements using Friedman tests.

We combined the eight Likert items into a single summated method performance scale (that is, a Likert scale) in order to evaluate whether any of the method types were given better or worse overall agreement scores than the others. This eight-item Likert scale demonstrated sufficient internal consistency (Cronbach's alpha $=0.86$ ). We excluded the 15 responses that provided answers for fewer than four of the Likert items. After excluding these responses, 72 (24 percent) responses and 124 (5 percent) items contained missing values, which included the "I don't know" and "not applicable" responses as well as the refusals. We replaced these missing values with the mean value for the item across all respondents because using the individual respondent mean value could have artificially inflated inter-item correlations (Downey and King 1998). The estimated Cronbach's alpha for these eight items remained the same after these replacements. We calculated means and 95-percent confidence intervals for the summated method performance scale and compared respondents' evaluation of the different dispute resolution method categories using a one-way ANOVA.

We used a four-way ANOVA to evaluate the main effects of primary professional training (engineering, biological sciences, physical sciences, social sciences, administration/business/contracts/realty), supervisory position (no, yes), and years worked at Reclamation ( $0-5$ years, $6-10$ years, $11-15$ years, $16-20$ years, $>20$ years) on respondents' score on the summated method performance scale. We excluded the other four primary professional training categories in this analysis because they had two or fewer responses.

\section{Dispute Resolution Professionals (DRPs)}

We calculated the median, mode, and the proportions of responses within each of the DRP affiliation types, and proportions within each category in the ordered-category scale that described the effect of the DRP on the resolution process. We compared the likelihood that respondents were more or less likely to report that DRPs had been used in conjunction with any of the dispute resolution method categories using a Pearson's Chi-square test and post hoc $z$ tests $(\alpha=0.05$ using a Bonferroni correction for multiple tests). We compared whether respondents rated the effect of the DRP differently depending on which dispute resolution method types were also used for the dispute using a Pearson's Chi-square test because some of the method categories had fewer than five responses. 


\section{Outcomes of Disputes over Science}

We calculated the proportions of responses within each of the dispute outcome categories ("the dispute was resolved," "the dispute resolution process is ongoing," "the dispute was not resolved and is not expected to be resolved," "I don't know").

The proportions of responses within each of the dispute outcome (excluding "I don't know" responses) were compared across the dispute resolution method categories using a Pearson's Chi-square test. The proportions of responses within each of the dispute outcome categories (excluding "I don't know" responses) were compared between disputes where a dispute resolution method had been used on disputes where no method was used using a Pearson's Chi-square test.

We used a GZLM with a multinomial distribution and logit link function to evaluate the main effects of primary professional training (engineering, biological sciences, physical sciences, social sciences, administration/business/contracts/realty), supervisory position (no, yes), and years worked at Reclamation ( $0-5$ years, $6-10$ years, $11-15$ years, $16-20$ years, $>20$ years) on dispute outcome (the dispute was resolved, the dispute is ongoing, the dispute was not resolved and is unlikely to be resolved in the future). We excluded the other four primary professional training categories in this analysis because they had two or fewer responses. Because the main effect of primary professional training was nonsignificant, and the main effect of supervisory role was nonsignificant when taking into account primary professional training, we re-ran a reduced GZLM without these variables.

We identified which categories of the number of years worked at Reclamation were more or less likely than expected to select the different decision outcomes using a Pearson's Chi-square test and post hoc $z$ tests ( $\alpha=0.05$ using a Bonferroni correction for multiple tests).

\section{Resolved Disputes over Science}

We calculated the proportion of responses within each of the dispute resolution location categories (within Reclamation, outside of Reclamation; I don't know).

\section{Outcomes of Decisions Hindered by Disputes over Science}

We calculated the proportion of responses within each of the decision outcome categories (the decision was made, the decision-making process is ongoing, the decision was not made and it is uncertain as to whether it will be made, I don't know).

We used a GZLM with a multinomial distribution and logit link function to evaluate the main effects of primary professional training (engineering, biological sciences, physical sciences, social sciences, administration/business/contracts/realty), supervisory position (no, yes), and the number of years worked at Reclamation ( $0-5$ years, $6-10$ years, $11-15$ years, 16-20 years, $>20$ years) on the decision outcome (the decision was made, the decision-making process is ongoing, the decision was not made and is unlikely to be made in the future). We excluded the other four primary professional training categories in this analysis because they had two or fewer responses. Because the main effect of primary professional training was nonsignificant, and the main effect of supervisory role was nonsignificant when taking into account primary professional training, we re-ran a reduced GZLM without these variables.

We identified which categories of the number of years worked at Reclamation were more or less likely than expected to select the different decision outcomes using a Pearson's Chi-square test and post hoc $z$ tests ( $\alpha=0.05$ using a Bonferroni correction for multiple tests).

The proportions of responses within each of the decision outcome categories (excluding "I don't know" responses) were compared across the dispute resolution method categories using a Pearson's 
Chi-square test. The proportions of responses within each of the decision outcome categories (excluding "I don't know" responses) were compared between disputes where a dispute resolution method had been used versus disputes where no method was used using a Pearson's Chi-square test.

\section{Experiences with Multiple Disputes over Science and (or) Dispute Resolution Methods}

We calculated the proportion of respondents that completed just one loop, two loops, or all three loops of the survey.

We used a GZLM with a multinomial distribution and logit link function to evaluate the main effects of primary professional training (engineering, biological sciences, physical sciences, social sciences, administration/business/contracts/realty), supervisory position (no, yes), and the number of years worked at Reclamation ( $0-5$ years, 6-10 years, 11-15 years, 16-20 years, $>20$ years) on the number of survey loops completed (one, two, three). We excluded the other four primary professional training categories in this analysis because they had two or fewer responses. Because the main effect of supervisory role was nonsignificant when taking into account primary professional training, and the main effect of number of years worked at Reclamation was nonsignificant when taking into account primary professional training and supervisory role, we re-ran a reduced GZLM without these variables.

We identified which primary professional training categories were more or less likely than expected to complete one, two, or three loops of the survey using a Pearson's Chi-square test and post hoc $z$ tests ( $\alpha=0.05$ using a Bonferroni correction for multiple tests).

\section{Evaluations of Dispute Resolution Resources for Reclamation Employees}

We calculated the median, mode, and the proportions of responses within each category in the ordered-category scale, which described the usefulness of each potential resource. We assessed which of the five potential resources respondents rated as being the most or least useful using a Friedman test and by comparing the median and mode for each factor. 


\section{Appendix 3}

\section{Glossary of Analyses}

Analysis of variance (ANOVA). A parametric statistical test of whether or not the means of different groups are equal. An ANOVA is a general linear model that assumes that cases are independent, the distribution of the residuals is normal, and that the groups' variances are equal. Non-normal, continuous data can often be transformed (that is, square-root transformation) so that it has a distribution that more closely approximates normal.

Bonferroni correction. A correction of the alpha level used for multiple significance tests in order to reduce the probability of false positives (that is, to reduce type I error).

Cronbach's alpha. An index of reliability or internal consistency across items (that is, questions, rankings, ratings, and so forth) for a sample. A higher value indicates that the test results have higher reliability.

Friedman test. A nonparametric statistical test that compares the distributions of ranks of repeated measures on a single sample.

Generalized linear model (GZLM). A generalization of ordinary least squares regression for non-normally distributed data that uses a link function to relate the linear model to the response variable. These tests are commonly used for binomial, ordinal, and count data, which do not follow the assumptions of general linear models. It is common practice that when the variation explained by one or more variables in the original model are not statistically significant, reduced models can be subsequently run that exclude these variables.

Independent-samples $t$ test. A statistical test that tests whether or not the means of two normally distributed independent samples are equal. Non-normal, continuous data can often be transformed (that is, square-root transformation) so that it has a distribution that more closely approximates normal. Kruskall-Wallis one-way analysis of variance. A nonparametric statistical test that compares the distribution of ranks across independent samples. A Kruskall-Wallis one-way ANOVA does not assume that the population approximates normal but does assume an identical scale and shape to the groups' distributions.

Likert item. A statement or question for which the respondent is asked to rank along a symmetric scale that depicts a range of intensity, such as agree to disagree. Likert items are often used with 5-point, 7point, or 9-point ordered-category scales with a neutral middle value.

Likert scale. A sum of responses to multiple Likert items or questions (that is, a summated scale). Likert scales are commonly used in survey research.

Pearson's chi-square test. A statistical test of independence that tests whether the frequency of paired observations of two categorical variables differs from what would be expected if the variables were independent. Post hoc tests (that is, Tukey or $z$ tests) can be used when one or both of the categorical variables have more than two categories to determine which pairs of cells in the contingency table are significantly different. Generally a Bonferroni correction is used with post hoc tests in order to reduce the probability of false positives. 
Publishing support provided by:

Denver Publishing Service Center

For more information concerning this publication, contact: Center Director, USGS Fort Collins Science Center

2150 Centre Ave., Bldg. C

Fort Collins, CO 80526-8118

(970) 226-9398

Or visit the Fort Collins Science Center Web site at: http://www.fort.usgs.gov/ 